\title{
A stochastic model for a macroscale hybrid renewable energy system
}

\author{
Ayse Selin Kocaman ${ }^{\mathrm{a}, *}$, Carlos Abad ${ }^{\mathrm{b}}$, Tara J. Troy ${ }^{\mathrm{c}}$, Woonghee Tim Huh ${ }^{\mathrm{d}}$, Vijay Modi ${ }^{\mathrm{e}}$ \\ a Department of Industrial Engineering, Bilkent University, Bilkent, Ankara, Turkey \\ b IEOR Department, Columbia University, NY, USA \\ ${ }^{\mathrm{c}}$ Department of Civil \& Environmental Engineering, Lehigh University, Bethlehem, PA, USA \\ ' Sauder School of Business, University of British Columbia, Vancouver, British Columbia, Canada \\ e Department of Mechanical Engineering and Earth Institute, Columbia University, NY, USA
}

\section{A R T I C L E I N F O}

\section{Article history:}

Received 17 March 2015

Received in revised form

16 July 2015

Accepted 6 October 2015

Available online 11 November 2015

\section{Keywords:}

Hydropower

Solar energy

Infrastructure sizing

Transmission network

Resource sharing

Two-stage stochastic program

India

\begin{abstract}
A B S T R A C T
The current supply for electricity generation mostly relies on fossil fuels, which are finite and pose a great threat to the environment. Therefore, energy models that involve clean and renewable energy sources are necessary to ease the concerns about the electricity generation needed to meet the projected demand. Here, we mathematically model a hybrid energy generation and allocation system where the intermittent solar generation is supported by conventional hydropower stations and diesel generation and time variability of the sources are balanced using the water stored in the reservoirs. We develop a two-stage stochastic model to capture the effect of streamflows which present significant inter-annual variability and uncertainty. Using sample case studies from India, we determine the required hydropower generation capacity and storage along with the minimal diesel usage to support $1 \mathrm{GW}_{\text {peak }}$ solar power generation. We compare isolated systems with the connected systems (through inter-regional transmission) to see the effects of geographic diversity on the infrastructure sizing and quantify the benefits of resource-sharing. We develop the optimal sizing relationship between solar and hydropower generation capacities given realistic cost parameters and real data and examine how this relationship would differ as the contribution of diesel is reduced. We also show that if the output of the solar power stations can be controlled (i.e. spill is allowed in our setting), operating them below their maximum energy generation levels may reduce the unit cost of the system.
\end{abstract}

(c) 2015 Elsevier Ltd. All rights reserved.

\section{Contents}

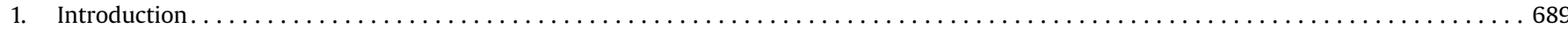

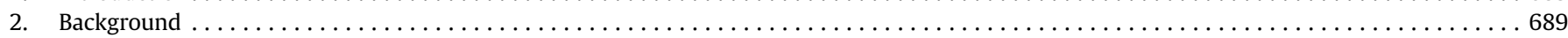

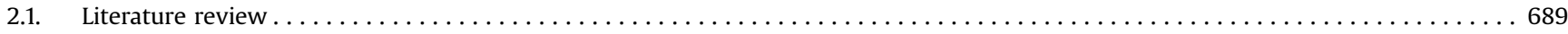

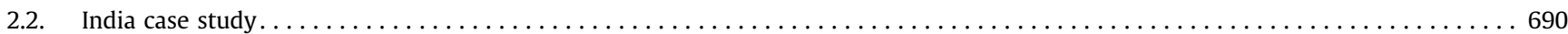

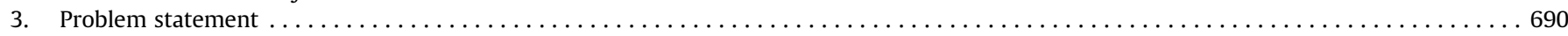

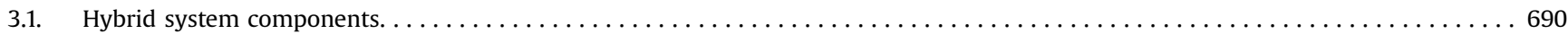

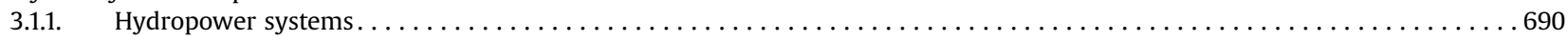

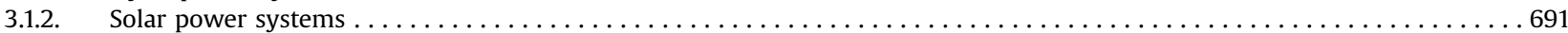

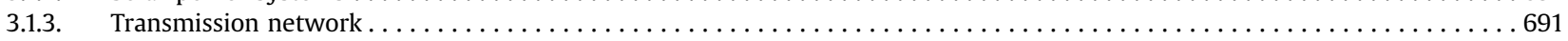

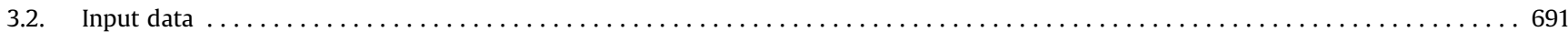

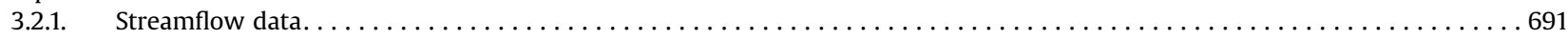

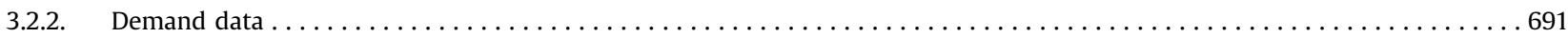

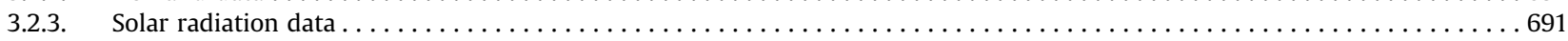

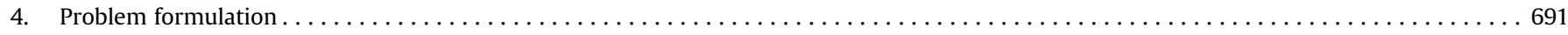

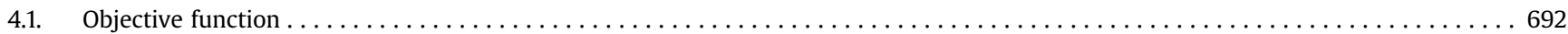

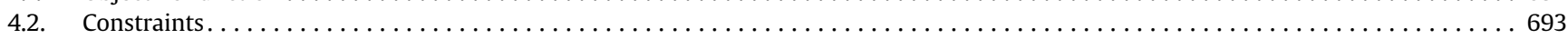

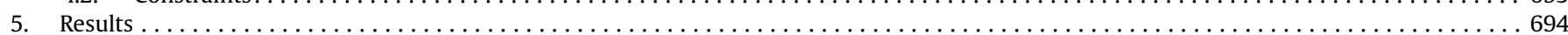

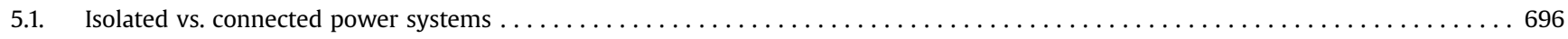

\footnotetext{
* Correspondence to: Bilkent Universitesi, Bilkent 06900, Ankara, Turkey. Tel.: +90 312290 3386; Fax: +90 3122664126.

E-mail address: selin.kocaman@bilkent.edu.tr (A. Selin Kocaman).
} 


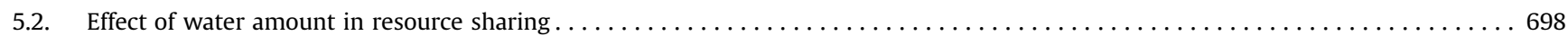

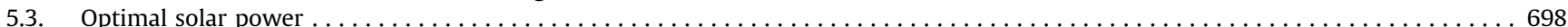

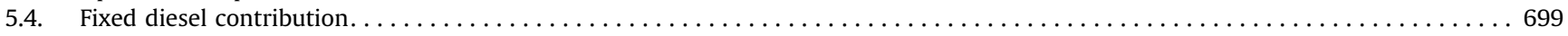

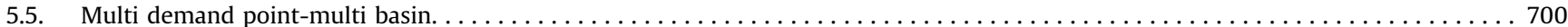

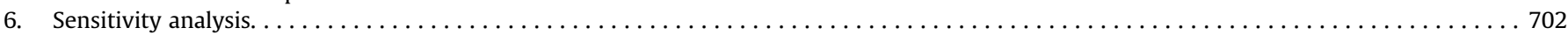

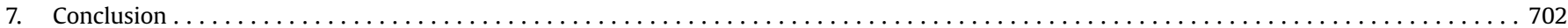

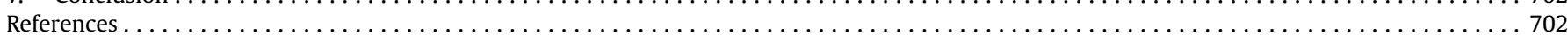

\section{Introduction}

The importance of sustainable energy planning has increased substantially with rising population growth rates, environmental issues and economic developments. The International Energy Agency (IEA) estimated that primary sources of electricity in 2012 consisted of $40.4 \%$ coal, $22.5 \%$ natural gas and $5 \%$ petroleum summing up to a $67.9 \%$ share for fossil fuels in primary electricity consumption in the world [1]. However, fossil fuels are finite and their combustion results in greenhouse gas emissions, which contribute to global warming and health hazards. Therefore, energy models that involve clean and renewable energy sources are necessitated to ease the concerns about the electricity generation needed to meet the projected demand.

The transition to alternative renewable energy sources is inevitable. However, renewable sources are temporally variable and heavily dependent on the spatial location (e.g. sunshine, while more predictable, is limited to daytime hours, and the total annual insolation is spatially varying. Annual wind energy potential is even more spatially heterogeneous.). Thus, if a future energy system is to predominantly rely on these sources, it must utilize a mix of variable and dispatch-able resources that are interconnected, thus requiring investments in transmission; utilize back-up dispatch-able resources (likely to be fossil fuels or hydro in the near term); and utilize some form of storage (e.g. pumped hydro or compressed air energy storage). Alternatively, one could allow some of the energy generated to be curtailed or use intelligent demand side management. For cost-effectiveness of the overall system, the approach is likely to involve "all of the above" [2-4].

Here, we consider the demand profiles and resources of a specific country and model the long-term investments and storage required to use variable and intermittent renewable sources together with minimal fossil fuel contribution. We want to demonstrate our results in the context of a developing country where the demand is growing fast and renewable power generation is quite promising. Hence, we use sample case studies from India. We mathematically model a hybrid energy generation and allocation system where the intermittent solar generation is supported by conventional hydropower stations and diesel generation. In conventional hydropower stations, incoming streamflows are stored in large reservoirs behind dams and hydropower production can be varied or deferred as per need. Using the high hydro power potential in the Himalaya Mountains, we determine the size of the hydropower generation capacity and reservoir sizes required to support fixed amount of peak solar capacity within the aggregated demand point locations (states of India). Since Himalayan streamflows also present significant seasonal and interannual variability, to increase the reliability of the system, diesel generators (as a proxy for expensive fossil resources) are used as a backup source.

We formulate our problem as a two-stage stochastic program where the inter-annual variability and uncertainty of streamflows are included in the form of scenarios. The first stage decisions include the sizing of energy infrastructure which are made before the random streamflows are realized and the second stage decisions are scenario-based operational decisions. The objective is to find the least-cost design for the power stations and transmission lines between basins and demand points while penalizing the diesel usage.

The main motivation of the model is to determine the optimal capacities of hydropower and solar power infrastructure needed to match projected demand and supply in the most cost effective way. We consider fine-grained sources of variability such as streamflow, solar radiation at the hourly level as well as spatial location of supply and demand in the national/regional level. With our sample case studies, we firstly show how much hydropower generation capacity and storage are needed along with minimal diesel usage to support $1 \mathrm{GW}_{\text {peak }}$ solar power generation. Then, we compare isolated systems with the connected systems (through inter-regional transmission) to see the effects of geographic diversity on the infrastructure sizing and quantify the benefits of resource-sharing. Moreover, given realistic cost parameters, real streamflow and solar radiation data, we determine the optimal solar and hydropower generation and distribution of the resources to meet the demand for different streamflow scenarios considered in the model and show how these contributions change throughout the year for one specific scenario. Finally, we show that if the output of the solar power stations can be controlled (i.e. spill is allowed), operating them below their maximum energy generation levels may reduce the unit cost of the system.

\section{Background}

\subsection{Literature review}

This study is related to some well-studied problems in the literature such as planning of hybrid energy systems and long-term energy investment planning problems.

The goal of a hybrid system is to obtain the most cost efficient system using alternative sources of energy. In order to obtain electricity reliably and economically, the hybrid system must be designed optimally in terms of operation and component selection. Many different hybrid systems which have been proposed in literature, involve renewable sources such as solar photovoltaic, wind and hydro with or without existence of storage alternatives such as pumped hydro or batteries [2-4]. Mathematical modeling and optimization of hybrid systems is not a trivial task as they usually involve many components and decision variables. Especially in the existence of storage, the fact that all time units in the planning horizon are linked to each other complicates the solution of the model. Therefore, to reduce the complexity of the models, hybrid systems have generally been proposed more for localized and decentralized systems that do not require the transmission component of the power systems. However, there is a need for feasibility studies in the literature which help understand contribution of the renewable sources in national energy system planning.

At the macrolevel, several national level energy planning models have been proposed [5-9]. These models provide policy makers with extensive details on energy generation and consumption technologies and how to meet some of the long-term goals related to government policies such as phasing out fossil fuels or decreasing greenhouse gas 
emissions. Previously proposed studies consider a time increment of 1 to 5 years and use the average values for energy sources and demand. However, it has been shown that models that utilize intermittent sources such as solar and wind tend to understate their value when averages are used [10]. These sources look more valuable when production periods are set to as short as a few hours. In addition, all these models use aggregated supply and demand without explicitly representing spatial locations and modeling transmission network. Therefore using these models, it is not possible to answer specific investment questions such as where to locate a solar power station or how to expand the transmission lines.

In our study, we focus on the long-term resource availabilities for hydro and solar and their interactions. To avoid complexity in our stochastic model, we neither model generator's grid operations with unit commitment problem nor include operational reserves. This approach is also consistent with our assumption that diesel as a proxy for expensive fossil resources is available whenever and as much as the system needs to meet the demand, however our approach may still underestimate the sizes of the generators and the unit cost of the overall system. The examples of some deterministic long term planning models which consider operational aspects of the grid such as unit commitment and regulatory reserves can be found in [11-14]. Moreover, an interesting study by Das et al. on high-fidelity dispatch modeling of storage technologies which examines the relationship between storage status and storage's participation in both energy and ancillary services can be found in [15].

\subsection{India case study}

India with 1.27 billion people, is the second most populous country in the world as of 2013. Nearly 25 percent of the population lacks basic access to electricity, and electrified areas suffer from electricity blackouts [16]. Moreover, India is currently the third-largest generator of coal-fired power after China and United States [16]. Therefore, the growing rate of energy consumption and heavy dependence on fossil fuels increase the importance of clean energy sources in order to be able to balance the need for electricity and address the environmental concerns for sustainable development in India.

India, with a vast land area, is very rich in terms of renewable energy sources like solar, hydro, wind and biomass [17]. The Himalayan ranges in the north with numerous perennial rivers and streams make hydropower one of the biggest renewable potentials in India. The streamflow occurs throughout the years and the steep slopes make all the streams potential sites for hydropower generation [18]. Moreover, India lies in the sunny belt of the world and is a very promising place for solar energy generation. The average intensity of solar radiation in India is $200 \mathrm{MW} / \mathrm{km}^{2}$ with $250-300$ sunny days per year [19]. Solar energy can also be used effectively to meet the increasing peak demand caused by the air conditioners, due to high correlation of solar radiation and cooling demand.

\section{Problem statement}

The goal of this paper is to see how combining multiple renewable sources which have different variability, storage and transmission can reduce the intermittency and variability of sources and increase the reliability of the power systems. We expect to help infrastructure planners make long-term investment decisions based on the results for energy resource allocation and storage over a one-year horizon. The objective of the model is to minimize the sum of the investment costs and expected penalty cost for the demand that cannot be met by renewable sources. In this system, water stored in the reservoirs can mitigate volatility of supply and demand. The reservoirs facilitate energy transfer from low use periods to peak use periods, allowing the system to operate based on demand load while maintaining high system reliability.

Storage is the key enabling technology for intermittent energy; however, it complicates the design of optimization problems by coupling all the time periods together. While working with sources that are not constantly available such as solar, the time increment that we use in the optimization model becomes quite important. To accurately capture the diurnal variability of streamflow and solar radiation, it is necessary to model energy supply and demand in hourly time increments. Moreover, because of the seasonal variability of the sources, it is also crucially important to use at least one year as the time horizon. An approach that avoids using every time increment over a year by simply sampling different time periods (e.g. different time of the years and time of the days) fails to accurately capture the storage dynamics. Moreover, modeling reservoir systems is principally more complicated than modeling other traditional storage systems such as batteries which usually operate with a daily cycle. Here, we may put water in reservoir storage months in advance from when it is used during the dry seasons.

The nature of hydropower generation, storage and the stochastic aspect of the key variables like streamflow, solar radiation and demand make the corresponding optimization problem quite difficult to be solved dynamically as a high number of units are involved. We use a typical strategy in stochastic programming where we solve a scenario based static optimization problem with multiple time periods that are coupled by storage. Scenarios with the associated probabilities represent possible random situations. Each scenario is a set of prototype 1-year series with 3 hourly time increments selected from the time series as a particular realization of the uncertain streamflow. A drawback of a scenario-based approach is the fact that scenarios are generated in advance, and this limits their ability to capture the interaction between decisions and exogenous events. We assume that the effect of this drawback can be minimized during the real-time operations of the power systems. For example, in the case of very rainy season which is not foreseen and captured by the scenarios, the water in the reservoirs can be controlled by the system operators during the season.

\subsection{Hybrid system components}

The hybrid model described in this paper has three sub-systems: hydropower stations, solar power stations and the transmission network between hydro and solar power stations. The design of individual power systems is not in the scope of this paper; therefore several assumptions are made to reduce the complexity of the model. System components and our assumptions are briefly summarized below and details can be seen in [20].

\subsubsection{Hydropower systems}

We identify several basins as candidate locations for hydropower stations and the output of the optimization problem is the size of the reservoirs and generators that determine the type and capacity of the power systems. We assume that pipeline sizes are linearly proportional to reservoir size and the pipe network cost can be included in reservoir cost. Moreover, empirical information shows that there is no operational cost based on the output level of the hydropower station [21]. In this model, we are interested in finding the size of multiple reservoirs, and we assume that each hydropower plant operates independently on a different river and is assigned to one reservoir. Due to frictions in the tunnel, turbines and generators, $12-14 \%$ of the potential energy of the water can be lost while generating electricity [21]. Therefore, we use $88 \%$ efficiency for all plants. Losses due to evaporation from the reservoirs are neglected. 
The potential for power production at a reservoir site mainly depends on the flow rate of water that can pass through generation turbines and the potential head available. Potential head usually depends on the topography and the constructed wall of the dam. Based on the design of the dams, the water level stored in the reservoirs can have an important influence on the energy potential of water. Given the steep slopes of the Himalayas, we assume in our settings that as in Norwegian statistics [21] the vertical height of a waterfall is measured from the intake to the turbines for the proof of concept. Thus, we use a constant head for each reservoir during the operations and do not consider the reduced electricity conversion efficiency, which is caused by the fact that the height of water falls is reduced as the reservoir is drawn.

Hydropower stations should be designed with care as they have highly site-specific concerns such as the effects of dams on fish, recreational activities and tourism or environmental constraints. There are two opposite views on the environmental and social impacts of Himalayan hydropower sites. The World Bank considers these sites as "among the most benign in the world" in terms of the social and environmental perspectives due to low population density in the areas [22]. However, other views argue that these sites would be more vulnerable to serious impacts of dam building [23]. In the hydropower projects, the effect of direct submergence of living areas, loss of resource base for agricultural activities, downstream impacts, and cultural impacts due to migration, ecological impacts, seismicity and sedimentation problems should be quantified as much as possible. These effects are not within the scope of this paper and will not be taken into account here. More discussion of these for the Himalayan hydropower sites can be found in $[22,23]$.

\subsubsection{Solar power systems}

The two main device types that are utilized for solar are photovoltaic (solar cells to generate electricity directly via the photoelectric effect) and concentrated solar power (capturing solar thermal energy for use in power producing heat processes). In both types, there exist techniques to enhance the efficiency such as designing the materials that absorb sunlight or sun-trackers that compensate for the Earth's motions by keeping the best orientation relative to the sun [24-26]. In our model, we use a simplistic approach and set the efficiency of solar power stations to $12 \%$ [24] and assume that solar power systems cost is linearly dependent on the size of the solar panels. Upfront capital costs dominate the operations and maintenance (O\&M) costs and are treated as "overnight" costs, i.e. it is assumed that the entire system investment is made at once.

\subsubsection{Transmission network}

Transmission cost in a power network usually depends on the capacity, distance from generation sites to demand points and related power losses in the lines. In our model, we use a process that allows us to have the transmission cost dependent on both the distance and the capacity of the lines. Details and results of this process can be seen in [20].

A loss parameter that is proportional to the distance can be easily incorporated into our model. Underground cable transporting and the cost for the stations have been also assumed to be proportional to the distance of the connection and included in the unit cost calculations. Possible network flow directions from sources to demand points are prescribed with dedicated lines and designed as a point-to-point topology. We do not model the grid itself nor consider real power flow equations/phase angle differences, and assume that power flows over lines can be independently assigned. This level of detail is mostly required for operational models and for certain types of regional planning models that aim to identify bottlenecks in the grid. This representation of power flows, which captures point-to-point movements without explicitly modeling the grid, is a common approximation made in policy studies [27-29]. A more detailed discussion on power flow and how it can be linearly modeled can be found in [30] and one can refer to [31-35] for the example studies which consider more detailed modeling of transmission system for longterm investment planning problems.

\subsection{Input data}

Aside from the physical features of the hybrid system, the model needs the three sets of input data: streamflow data for each candidate hydropower locations, solar radiation data and demand profile for each demand point.

\subsubsection{Streamflow data}

Forecasting the inflows and capturing the structure of the processes is of vital importance to hydropower models. This issue is discussed in detail in [36]. For our model we identified several basins from [23] in the Himalaya Mountains which are either proposed or under construction areas for hydropower generation. 3-hourly (3-h) streamflow data for each candidate basins between 1951 and 2004 was obtained from the Variable Infiltration Capacity (VIC) land surface model which is a large scale hydrological model. This model can be implemented at grid cells from $1 / 8^{\circ}$ to $2^{\circ}$ latitude by longitude and with temporal resolutions from hourly to daily. For this study, the VIC model is run at $1^{\circ}$ at $3-\mathrm{h}$ resolutions. The details of the VIC model can be found in [37,38]. The VIC model here is the same set-up as [39] and is forced using the Princeton Global forcing dataset [40]. General statistics about basins and details of the data are given in Table 1.

\subsubsection{Demand data}

Aggregated electricity demand data in 3-h resolution was collected for Delhi and seven other states located in the northern part of India from the websites of the Central Electricity Authority, the Power Ministry of India (CEA) and the Load Dispatch Centers [41]. We use the collected data to accurately estimate the 3-h demand load profile of each state for one year using interpolation/extrapolation techniques. The final data can be obtained from [20].

The location of the basins and demand points are presented in Fig. 3. The list of the states with the estimated annual demand for the year 2012 is provided in Table 2. Population data provided in Table 2 is based on the 2011 Population Census [42].

The daily load profiles of Delhi for the days where the peak demand is observed in each month in 2012 are presented in Fig. 1. The highest demand is observed in summer months, while the lowest is observed in winter months. The fact that the highest demand occurs in summer and daily peak demand is observed in the afternoon can be explained by the increasing cooling demand during the summer months. In winter, it is possible to observe two peaks in the daily load profile, one in the morning and one in the evening. In Fig. 2 we present the monthly total demand of the ten states listed in Table 2.

\subsubsection{Solar radiation data}

Site and time specific high resolution solar radiation data was obtained by the U.S. National Renewable Energy Laboratory (NREL) in cooperation with India's Ministry of New and Renewable Energy using weather satellite. Global and direct irradiance at hourly intervals on the 10-km grid for all of India for the years 2001-2008 is available on NREL's website [43]. The hourly solar radiation data for all demand points used in the model is presented in Table 3.

\section{Problem formulation}

We formulate our problem as a two-stage stochastic program where the first stage decisions include the sizing of energy infrastructure and the second stage decisions are scenario-based 
Table 1

General statistics for basins.

\begin{tabular}{|c|c|c|c|c|c|c|c|c|c|}
\hline \multirow[t]{2}{*}{ No } & \multirow[t]{2}{*}{ River } & \multirow[t]{2}{*}{ Project } & \multirow[t]{2}{*}{ Lat $\left({ }^{\circ} \mathrm{E}\right)$} & \multirow[t]{2}{*}{ Long $\left({ }^{\circ} \mathrm{N}\right)$} & \multicolumn{5}{|c|}{ Period 1951-2004 (Stream Flow m³ $/ \mathrm{s}$ ) } \\
\hline & & & & & Minimum & Maximum & Average & Standard deviation & Coefficient of variation \\
\hline 1 & Bhagirathi & Tehri & 30.38 & 78.48 & 2 & 36,550 & 217 & 592 & 2.73 \\
\hline 2 & Pinder & Devsari & 30.41 & 79.37 & 0 & 13,734 & 165 & 230 & 1.39 \\
\hline 3 & Chenab & Pakal Dul & 33.46 & 75.81 & 169 & 48,334 & 1765 & 1957 & 1.11 \\
\hline 4 & Marusudar & Bursar & 33.29 & 75.76 & 44 & 12,749 & 466 & 516 & 1.11 \\
\hline 5 & Lohit & Demwe & 28.03 & 96.45 & 77 & 18,915 & 599 & 616 & 1.03 \\
\hline 6 & Dibang & Dibang & 28.34 & 95.78 & 46 & 21,362 & 284 & 305 & 1.08 \\
\hline 7 & Barak & Tipaimukh & 24.23 & 93.02 & 0 & 46,528 & 2086 & 1968 & 0.94 \\
\hline 8 & Siang & Siang & 28.17 & 95.23 & 878 & $1,863,500$ & 13,879 & 23,303 & 1.68 \\
\hline
\end{tabular}

Table 2

List of states used as aggregated demand points.

\begin{tabular}{lcll}
\hline & $\begin{array}{l}\text { Population (Million) } \\
(2011 \text { Census) }\end{array}$ & $\begin{array}{l}\text { Estimated Annual } \\
\text { Demand in 2012 } \\
\text { (GWh) }\end{array}$ & $\begin{array}{l}\text { Load } \\
\text { factor }\end{array}$ \\
\hline Delhi & 16.8 & 30,013 & 0.71 \\
Punjab & 27.7 & 47,534 & 0.59 \\
Uttaranchal & 10.1 & 12,786 & 0.82 \\
Himachal Pradesh & 6.9 & 7,744 & 0.72 \\
Uttar Pradesh & 199.6 & 87,916 & 0.79 \\
Bihar & 103.8 & 13,774 & 0.76 \\
West Bengal & 91.3 & 40,777 & 0.79 \\
Jharkhand & 33 & 5663 & 0.78 \\
Assam & 31.2 & 5162 & 0.63 \\
Chhattisgarh & 25.5 & 17,718 & 0.81 \\
\hline
\end{tabular}

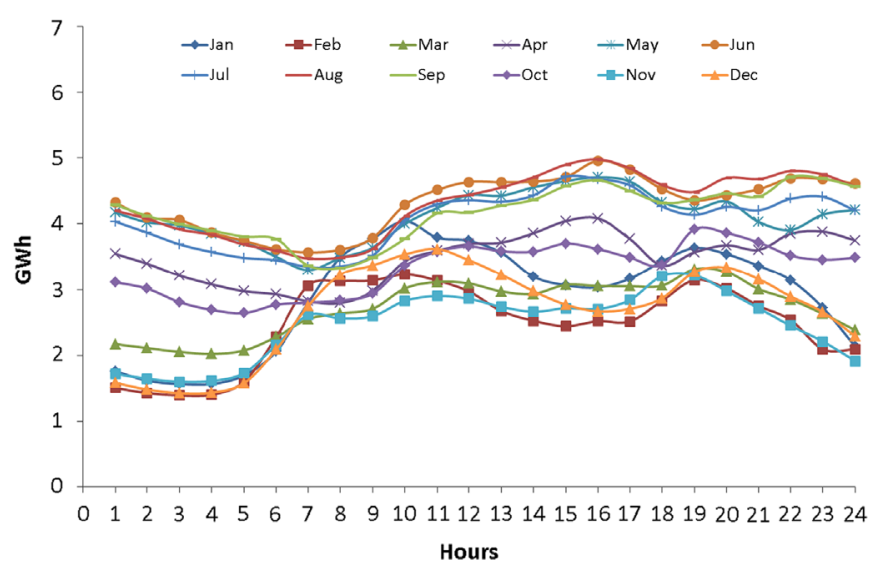

Fig. 1. Daily demand profile of Delhi in 2012.

operational decisions. A standard form of the two-stage stochastic program can be written as follows:

$\min c^{T} x+E_{\omega} Q(x, \omega)$

st. $A x=b$

$x \geq 0$

whereQ $(x, \omega)=\min \left\{d_{\omega}^{T} y T_{\omega} x+W_{\omega} y=h_{\omega}, y \geq 0\right\}$

In two-stage stochastic programs, we have a set of decision to be taken before some random events are realized. These decisions are called first-stage decisions and are usually represented by $\mathrm{x}$. After the realization of stochastic variable $\omega$, second stage actions $y$

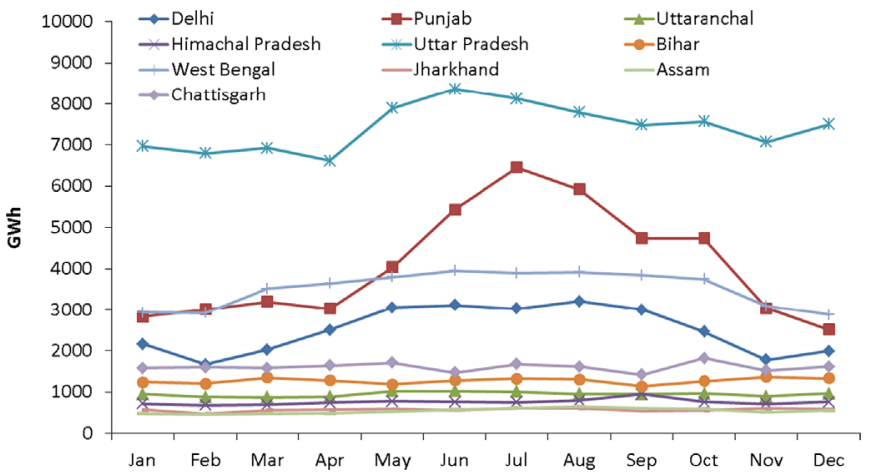

Fig. 2. Monthly total demand of ten states in India in 2012.

are taken. In the standard form, $E_{\omega}$ is the expectation and $\omega$ denotes a scenario with respect to the probability $\operatorname{space}(\Omega, P)$. When we consider a discrete distribution $\mathrm{P}$, then we can write

$E_{\omega} Q(x, \omega)=\sum_{\omega \in \Omega} p(\omega) Q(x, \omega)$

The extensive form of the two-stage program, then can be written as follows:

$\min c^{T} x+\sum_{\omega} p(\omega) d_{\omega}^{T} y_{\omega}$

st. $A x=b$

$T_{\omega} x+W_{\omega} y_{\omega}=h_{\omega} \forall \omega$

$x \geq 0, y_{\omega} \geq 0$

The following model is the extensive form of the two-stage stochastic program as we explicitly describe the second stage decision variables for all scenarios. Tables 4-6 summarize the indices, parameters and variables used in the model. Among the variables, the ones indexed by $\omega$ correspond to our second stage variables. Reservoir sizes, generator sizes, solar panel areas and transmission line sizes correspond to our first stage decisions.

\subsection{Objective function}

The objective of the model is to minimize the sum of annualized investment costs and expected penalty cost for the mismatched demand (assumed to be met by diesel). Unit costs of investments are assumed to be equal to the constant incremental cost of installing capacities and indexed by the location so that different 


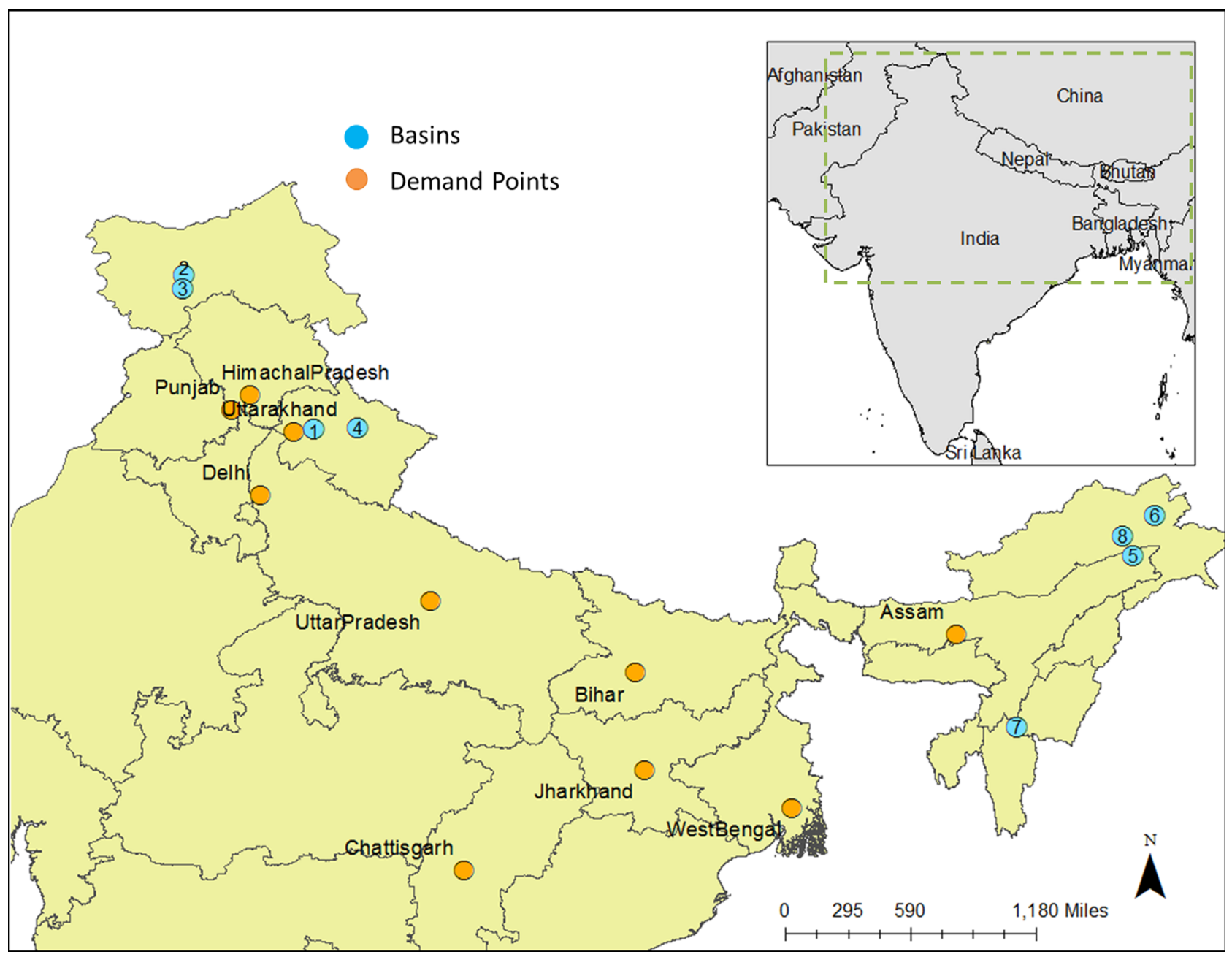

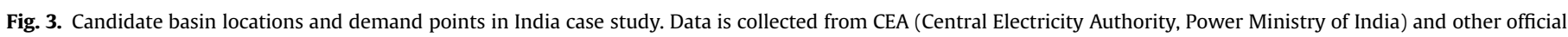

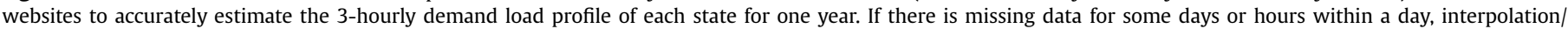
extrapolation methods are performed for projection.

costs parameters can be used for different locations. The objective function has five components:

\section{i. Cost of Reservoirs:}

$$
C_{1}=\sum_{i} C_{S i} * \operatorname{Smax}_{i}
$$

ii. Cost of Hydropower Generators:

$$
C_{2}=\sum_{i} C_{P G i} * P G \max _{i}
$$

iii. Cost of Solar Power Stations:

$$
C_{3}=\sum_{j} C_{M j} * M_{j}
$$

iv. Cost of Transmission Lines:

$$
C_{4}=\sum_{i} \sum_{j} C_{T i j} * T \max _{i j}
$$

v. Expected Cost of Mismatched Demand:

$$
C_{5}=\sum_{j t \omega} p_{\omega} * Z_{j}^{\omega t} * \mu_{j}
$$

Objective function can be stated as: $\min \left(C_{1}+C_{2}\right) * d_{h}+C_{3} * d_{s}+C_{4} * d_{t}+C_{5}$

\subsection{Constraints}

The equality and inequality constraints of the problem are stated below:

$$
\begin{aligned}
& S_{i}^{\omega t} \leq \operatorname{Smax}_{i} \quad \forall i, t, \omega \\
& S_{i}^{\omega t}=S_{i}^{\omega(t-1)}+W_{i}^{\omega t}-R_{i}^{\omega t}-L_{i}^{\omega t} \quad \forall i, t: t>1, \omega \\
& S_{i}^{\omega 1}=\operatorname{Smax}_{i}+W_{i}^{\omega 1}-R_{i}^{\omega 1}-L_{i}^{\omega 1} \quad \forall i, \omega \\
& S_{i}^{\omega T}=\operatorname{Smax}_{i} \quad \forall i, \omega \\
& f_{G i}\left(R_{i}^{\omega t}\right) \leq P G \max _{i} * n \quad \forall i, t, \omega \\
& \sum_{j} T_{i j}^{\omega t}=f_{G i}\left(R_{i}^{\omega t}\right) \quad \forall i, t, \omega \\
& T_{i j}^{\omega t} \leq \operatorname{Tmax}_{i j} * n \quad \forall i, j, t, \omega \\
& D_{j}^{\omega t} \leq Z_{j}^{\omega t}+f_{S j}\left(M_{j}\right)+\sum_{i} T_{i j}^{\omega t} *\left(1-l_{i j}\right) \quad \forall j, t, \omega \\
& S_{i}^{\omega t}, \operatorname{Smax}_{i}, P G \max _{i}, R_{i}^{\omega t}, L_{i}^{\omega t}, M_{j}, T_{i j}^{\omega t}, \operatorname{Tmax}_{i j}, Z_{j}^{\omega t} \geq 0 \quad \forall i, j, t, \omega
\end{aligned}
$$

The constraint (1) ensures that water stored in the reservoir is limited by the size of the reservoir at each time period for every 
Table 3

Solar Radiation Data.

\begin{tabular}{|c|c|c|c|c|c|c|c|}
\hline & Lat $\left({ }^{\circ} \mathrm{E}\right)$ & Long $\left({ }^{\circ} \mathrm{N}\right)$ & \multicolumn{5}{|c|}{ Period 2001-2008 (Global Horizontal Irradiance : W/m²) } \\
\hline Delhi & 29.02 & 77.38 & 0 & 1004 & 213 & 295 & 1.38 \\
\hline Uttaranchal & 30.33 & 78.06 & 0 & 998 & 209 & 289 & 1.38 \\
\hline Himachal Pradesh & 31.10 & 77.17 & 0 & 1013 & 213 & 292 & 1.37 \\
\hline Uttar Pradesh & 26.85 & 80.91 & 0 & 1002 & 221 & 320 & 1.45 \\
\hline Bihar & 25.37 & 85.13 & 0 & 1006 & 221 & 321 & 1.45 \\
\hline Assam & 26.14 & 91.77 & 0 & 974 & 193 & 273 & 1.41 \\
\hline Chhattisgarh & 21.27 & 81.60 & 0 & 1003 & 232 & 312 & 1.34 \\
\hline
\end{tabular}

Table 4

Indices for parameters and decision variables.

\begin{tabular}{ll}
\hline$i:$ & hydropower station $1, \ldots, \mathrm{I}$, with a total of I locations \\
$j:$ & demand (solar power station) point $1, \ldots, \mathrm{J}$, with a total of J points \\
$t:$ & time period $1, \ldots, \mathrm{T}$, with a total of T periods \\
$\omega:$ & scenarios $1, \ldots, \Omega$, with a total of $\Omega$ scenarios
\end{tabular}

\section{Table 5}

Parameters of the model.
Table 7

Parameters used in the model.

\begin{tabular}{llll}
\hline Unit Cost of Reservoir Capacity, $C_{s S i}$ & $\$ 3 / \mathrm{m}^{3}$ & $\forall \mathrm{i}$ & {$[46,47]$} \\
Unit Cost of Generator Capacity, $C_{P G i}$ & $\$ 500 / \mathrm{kW}$ & $\forall \mathrm{i}$ & {$[48]$} \\
Unit Cost of Solar Array, $C_{M j}$ & $\$ 200 / \mathrm{m}^{2}$ & $\forall \mathrm{j}$ & {$[48,49]$} \\
Unit Cost of Diesel, $\mu_{j}$ & $\$ 0.25 /$ & $\forall \mathrm{j}$ & {$[50,51]$} \\
& $\mathrm{kWh}$ & & \\
Efficiency of Hydropower System, $\alpha$ & $88 \%$ & - & {$[21]$} \\
Efficiency of Solar Panels, $\gamma$ & $12 \%$ & - & {$[26]$} \\
Discount Rate: & $5 \%$ & - & {$[52]$} \\
Life Time, hydro: & 60 years & $\forall \mathrm{i}$ & {$[53]$} \\
Life Time, solar: & 30 years & $\forall \mathrm{j}$ & {$[54,55]$} \\
Life Time, transmission: & 40 years & $\forall \mathrm{i}, \mathrm{j}$ & {$[56]$} \\
\hline
\end{tabular}

scenario. Constraints (2)-(4) represent the mass balance equations in reservoirs. Constraint (2) couples the reservoir levels between subsequent time periods. In (3) and (4), beginning and ending balance of reservoirs are set. Here, we assume that operations begin and end with full reservoirs at each scenario. In our model, scenarios start in September, which is almost end of the monsoon season in India, and finish in August of the following year. Thus, it is reasonable to assume that reservoirs would be full at this time of the year. The constraint (5) ensures that generated energy is defined by $f_{G i}\left(R_{i}^{\omega t}\right)=R_{i}^{\omega t} * g * h_{i} * \alpha$ and is limited by the generator capacity at each time period of every scenario. The constraint (6) ensures that at any period in any scenario, total energy transmitted to the demand points from a hydropower station is equal to generated energy in that hydropower station. The constraint (7) ensures that transmitted energy is limited by the transmission line capacity. The constraint (8) ensures that demand $D_{j}^{\omega t}$ is met by the sum of the energy transmitted from hydropower stations, energy generated in solar power stations and energy generated using diesel generators in demand point $\mathrm{j}$ during time period $\mathrm{t}$ in scenario $\omega$. Energy generated in solar power stations is defined by the function $f_{S j}\left(M_{j}\right)$ where $f_{S j}\left(M_{j}\right)=N_{j}^{\omega t} * M_{j} * \gamma$.

\section{Results}

The optimization problem whose objective is to minimize the sum of the costs (i)-(v) subject to the constraints (1)-(9) is a linear program. We use IBM ILOG CPLEX Optimization Studio (CPLEX) [44] to solve it. We present multiple instances of the India case study to emphasize the different aspects of our model. Here, we present the results of our algorithm described above. In Section 5.1, we first discuss that having a connected power system where the basins are linked to each other with transmission lines will be beneficial both analytically and numerically compared to having isolated systems. In this stochastic analysis involving the uncertainty of the renewables, we scale the demand of the states and the solar power generation to $1 \mathrm{GW}_{\text {peak. }}$ Then, 
we scale the streamflow data and analyze the effect of available water amount in Section 5.2. Next, in Section 5.3, we relax the constraint on the solar power radiation to obtain the optimal solar panel area and observe how the results deviate from the results found earlier. Furthermore, in Section 5.4, we analyze the trend in the solution parameters assuming a fixed amount of diesel is available. Finally in Section 5.5, we repeat the analysis in Section 5.1 for all the basins and demand points of India considered in this study.

Parameters that are used in the analysis of the data are shown in Table 7. Cost parameters are given in 2013 USD. In next section, we also assess the sensitivity of the system in terms of cost parameters. Here, we optimize the investments and operations over a year by considering the annual investment cost. For this, dimensionless annualization parameters are calculated based on the lifetime of the technologies and discount rate given in Table 7, using the formula, annualization parameter $=i /\left(1-(1+i)^{-\mathrm{LT}}\right)$, where lifetime and the interest rate are denoted by LT and $i$, respectively. With this approach, we implicitly mitigate the end-effects of the infrastructure due to fixed planning horizon, using a similar approach to salvage value approach which takes the operating life of the infrastructure after the planning horizon in the simulation or optimization models into account. An extensive study by Krishnan et al., on end-effect mitigation can be found in [45].
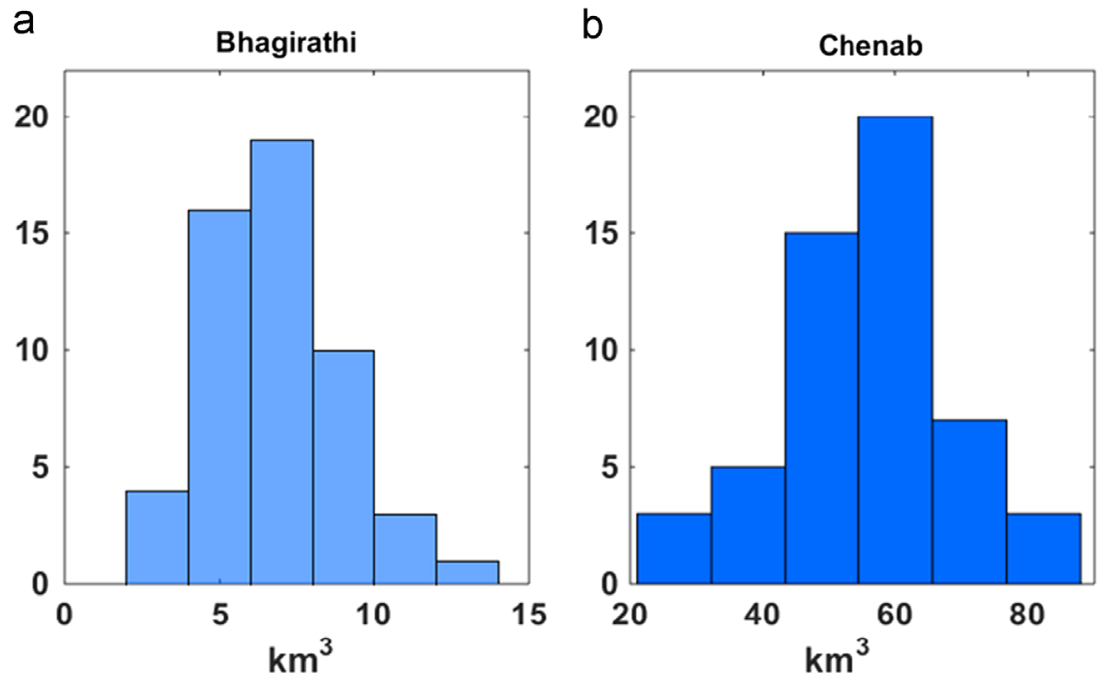

Fig. 4. (a) Distribution of 53 streamflow scenarios for Bhagirathi River, and (b) distribution of 53 streamflow scenarios for Chenab River.

a

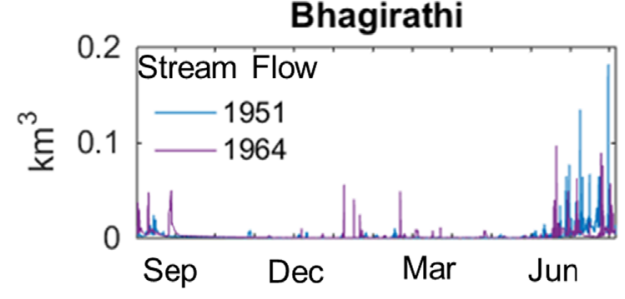

C

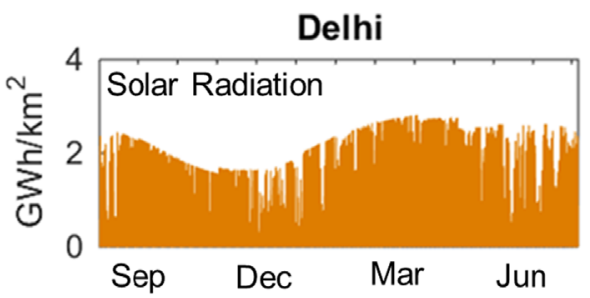

e

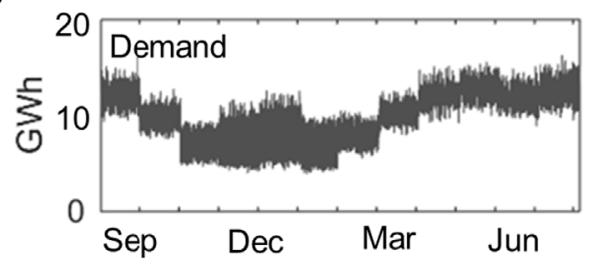

b

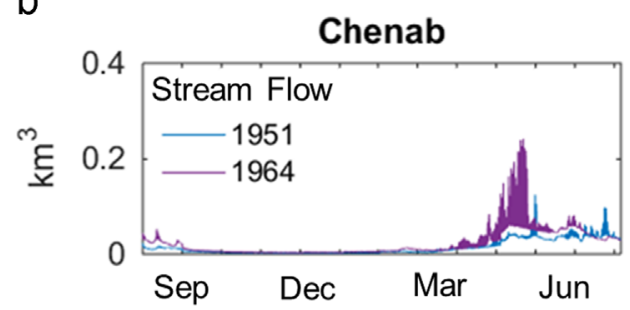

d

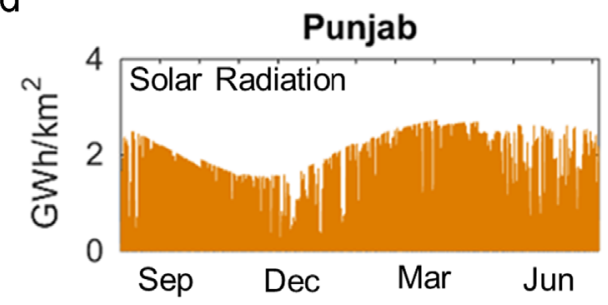

f

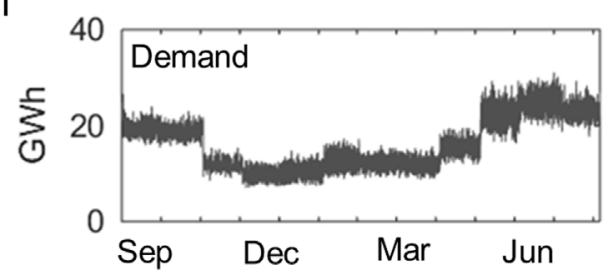

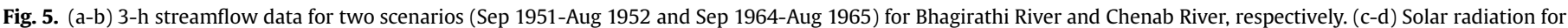
every three hour per kilometer square for the year 2002 in Delhi and Punjab, respectively. (e-f) Demand load curves for one year in Delhi and Punjab, respectively. 


\subsection{Isolated vs. connected power systems}

In this section, we quantitatively show the benefits of resource sharing and transmission lines using a sample system which includes two demand points, Delhi and Punjab and two basins, Bhagirathi and Chenab. We compare the isolated, single-basin/single-demand point cases (Delhi-Bhagirathi and Punjab-Chenab) with the integrated, twobasin/two-demand point cases as shown in Figs. 6a,b and 7a.

In the integrated, two-basin/two-demand point model, if we set the size of the transmission lines which connect isolated systems together to zero with extra constraints, then the optimal solution of the model with extra constraints will be the same with the optimal solution for the isolated cases. This additional constraint will make the solution space of our integrated system smaller and the new objective will be higher than or equal to the objective of unconstrained model in a minimization problem setting. Therefore, mathematically, our integrated model will always find at least as good solution as the isolated cases. Moreover, as isolated systems get connected to each other with the transmission lines, it can also be expected logically that the variability and the intermittency of renewable sources are smoothed out due to resource sharing and this helps getting a better solution.

To illustrate this effect numerically, we examine the sample system by scaling the demand of the states to $1 \mathrm{GW}_{\text {peak. }}$ With this analysis, we also want to analyze the hydropower generation and storage capacity needed to support $1 \mathrm{GW}_{\text {peak }}$ solar capacity and solar power generation is also fixed to $1 \mathrm{GW}_{\text {peak }}$ for both states by setting a constraint in the model and fixing the solar panel areas to a

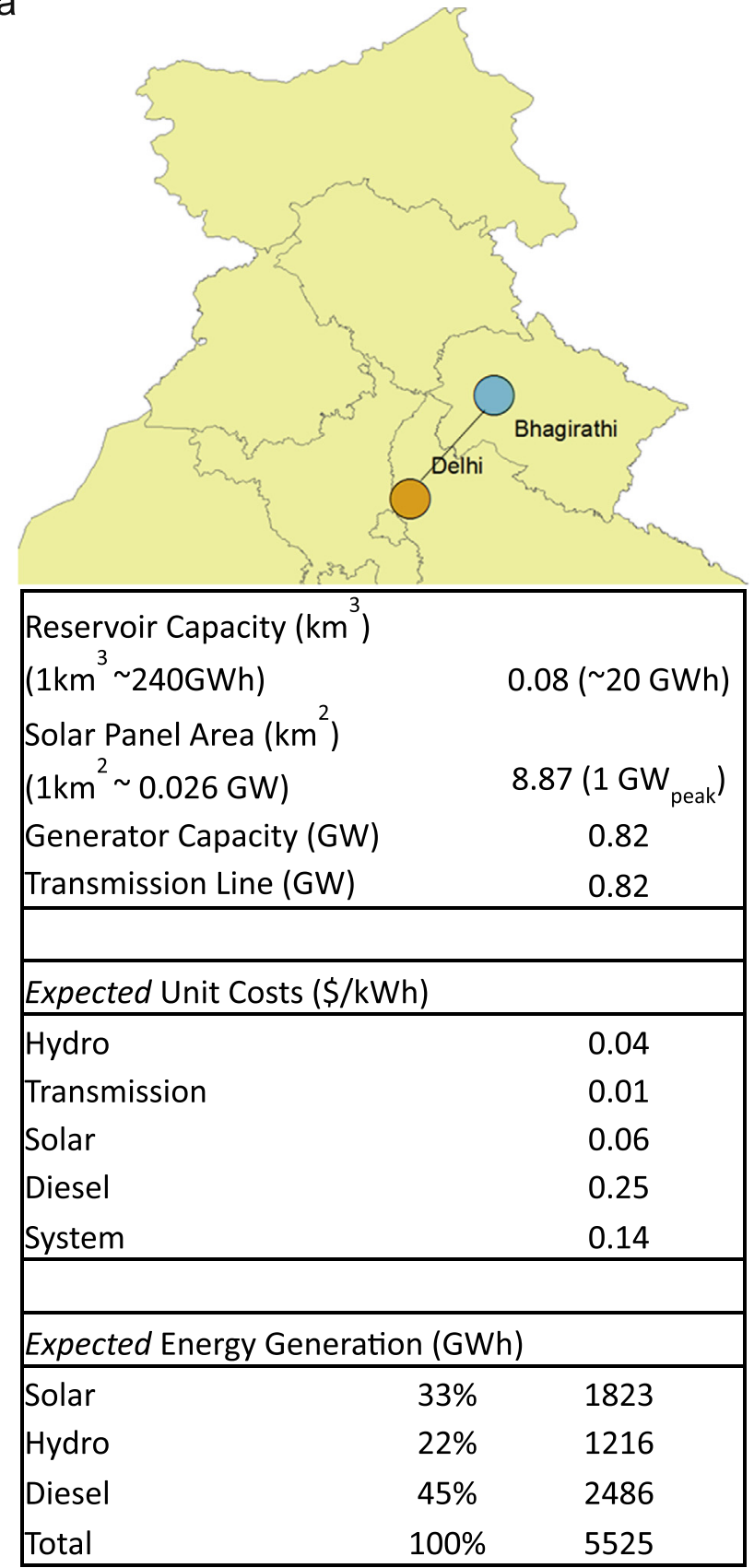

b

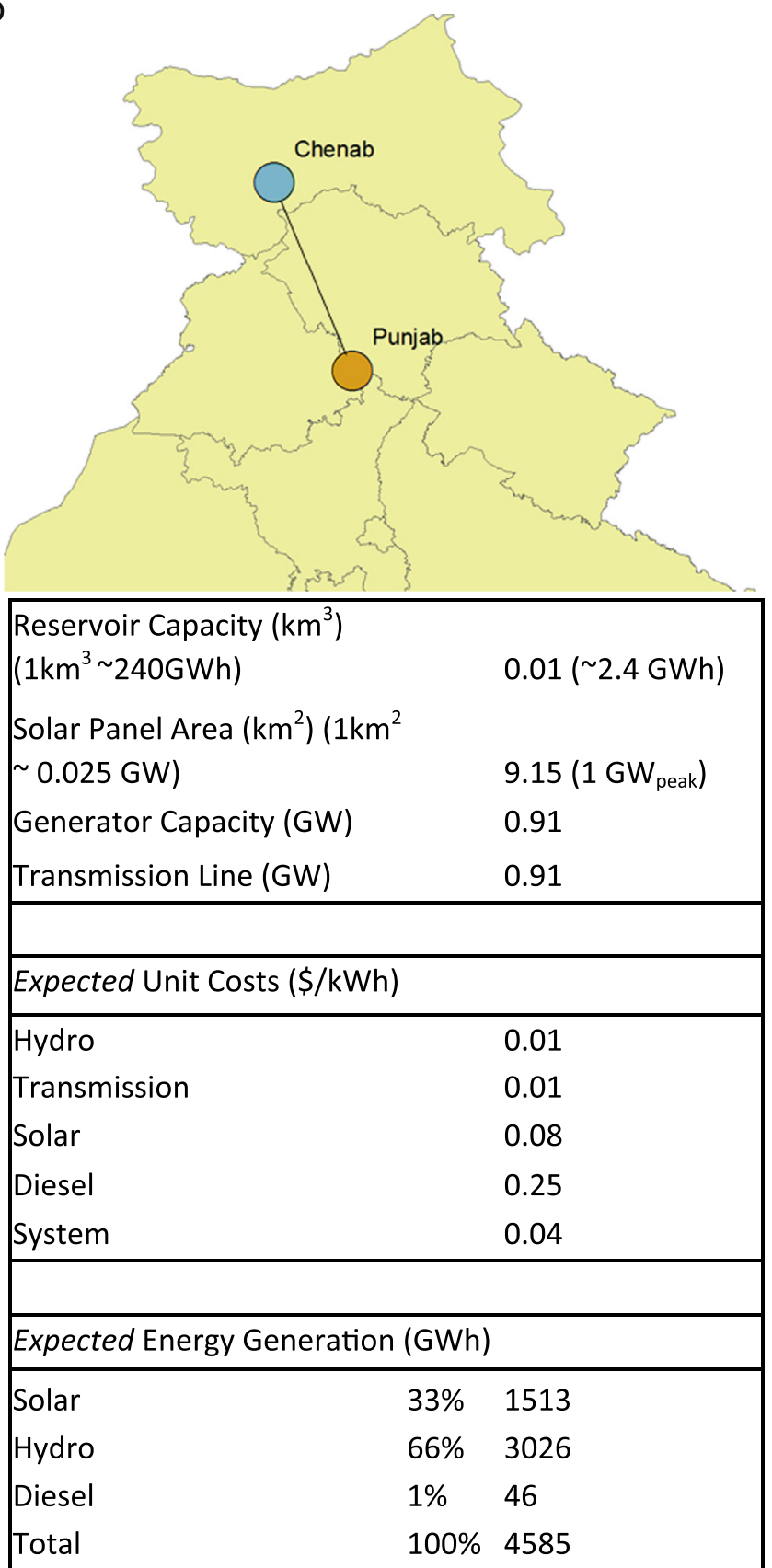

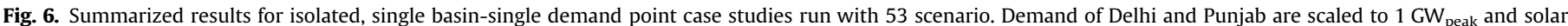
panel areas are set to $8.87 \mathrm{~km}^{2}$ and $9.15 \mathrm{~km}^{2}$ for Delhi and Punjab, respectively based on the peak solar radiation to provide $1 \mathrm{GW}_{\text {peak }}$ power. 
$8.87 \mathrm{~km}^{2}$ and $9.15 \mathrm{~km}^{2}$ for Delhi and Punjab, respectively. First, the results for isolated systems (Delhi - Bhagirathi and Punjab- Chenab) are obtained individually and these results are compared to the results of integrated, co-optimized (two-demand point, twobasin case) case.

Compared to solar radiation and demand, we observe highly significant inter-annual variability and uncertainty in the streamflow data. To be able to capture the effect of annual streamflow uncertainty on the infrastructure sizes, we take a naïve approach and consider each year in our 53-year time series data as a different scenario with the same probability. Therefore, we ran our stochastic model for the 53 scenarios of the streamflow. Fig. 4 shows the distribution of annual streamflow for our 53 scenarios for both Bhagirathi and Chenab rivers. The annual streamflow

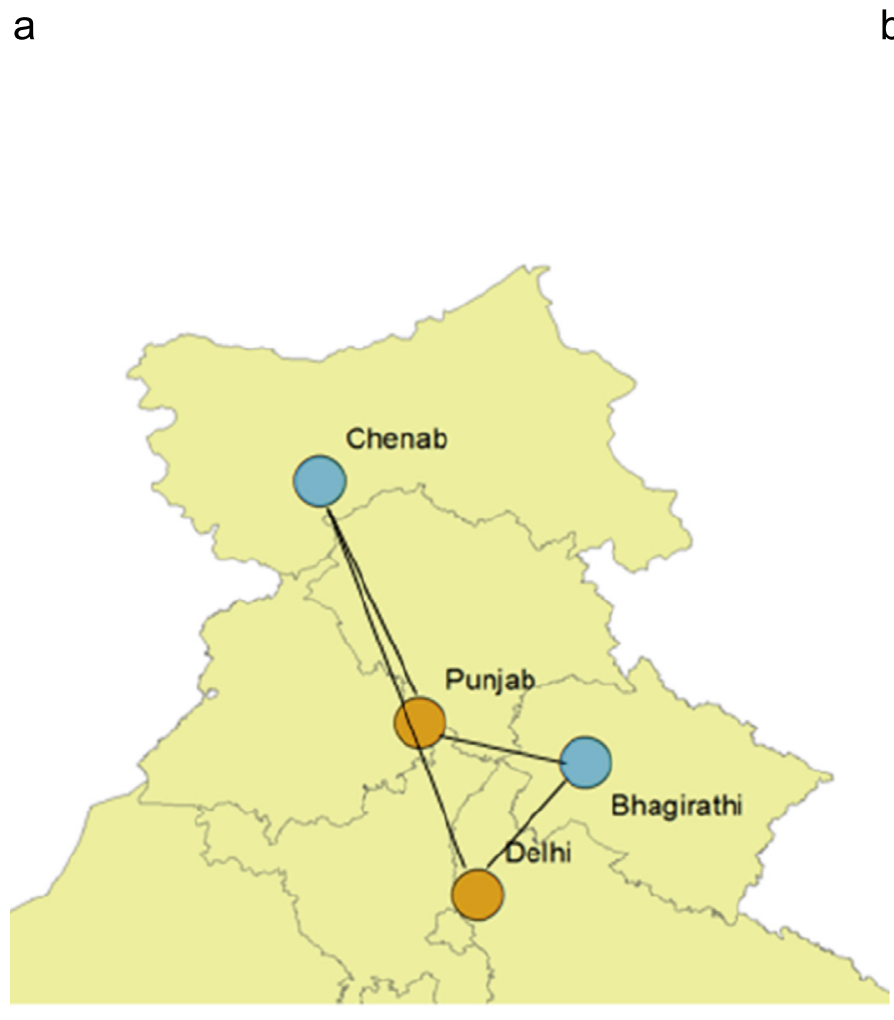

between the years 1951 and 2003 varies between $3 \mathrm{~km}^{3}$ and $14 \mathrm{~km}^{3}$ in the Bhagirathi River and $20 \mathrm{~km}^{3}$ and $90 \mathrm{~km}^{3}$ in the Chenab River. These variations show the necessity of using a stochastic approach while sizing the systems. Demand and solar radiation time series for Delhi and Punjab used in the analysis are presented in Fig. 5.

The results of this analysis are summarized in Figs. 6 and 7. It is shown that the expected sum of diesel contribution can be decreased by $70 \%$ (from $2532 \mathrm{GWh}$ to $757 \mathrm{GWh}$ ) if the integrated power systems are designed instead of isolated systems. The required storage size can also decreased up to $40 \%\left(0.09 \mathrm{~km}^{3}\right.$ to $\left.0.055 \mathrm{~km}^{3}\right)$. Instead of generating electricity for $₫ 14.2 \mathrm{kWh}^{-1}$ in Delhi-Bhagirathi and $\mathbb{\uparrow}$ $3.8 \mathrm{kWh}^{-1}$ in Punjab-Chenab isolated cases, the hydropower potential can be shared between two states in expense of two additional

b

\begin{tabular}{|c|c|}
\hline & Bhagirathi \\
\hline ReservoirSize $\left(\mathrm{km}^{3}\right)$ & $\begin{array}{l}0.03 \\
(\sim 7.2 \mathrm{GWh})\end{array}$ \\
\hline GeneratorSize (GW) & 0.26 \\
\hline \multicolumn{2}{|c|}{ TransmissionLine to (GW) } \\
\hline Delhi & 0.15 \\
\hline Punjab & 0.21 \\
\hline \multicolumn{2}{|l|}{ SolarPanelSize $\left(\mathrm{km}^{2}\right)$} \\
\hline Delhi & $8.87\left(1 \mathrm{GW}_{\text {peak }}\right)$ \\
\hline Punjab & $9.15\left(1 \mathrm{GW}_{\text {peak }}\right)$ \\
\hline \multicolumn{2}{|c|}{ Expected Unit Costs (\$/kWh) } \\
\hline Hydro & 0.01 \\
\hline Transmission & 0.01 \\
\hline Solar & 0.07 \\
\hline Diesel & 0.25 \\
\hline System & 0.05 \\
\hline
\end{tabular}

C

\begin{tabular}{|l|c|c|c|c|}
\cline { 2 - 5 } \multicolumn{1}{c|}{} & \multicolumn{2}{c|}{ Delhi } & \multicolumn{2}{c|}{ Punjab } \\
\hline Expected Energy Generation & GWh & \% Demand & GWh & \% Demand \\
\hline Solar & 1769 & $32 \%$ & 1465 & $61 \%$ \\
Hydro & 3335 & $60 \%$ & 2784 & $7 \%$ \\
Diesel & 421 & $8 \%$ & 336 & $100 \%$ \\
\hline
\end{tabular}

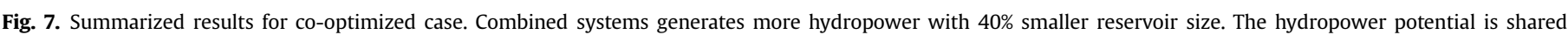

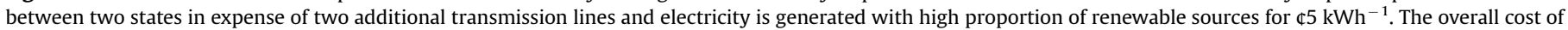
the objective function is decreased by $46 \%$. 
transmission lines and electricity can be generated with high proportion of renewable sources for $₫ 5.1 \mathrm{kWh}^{-1}$. The overall cost of the objective function can be decreased by $46 \%$.

In this sample case study, Chenab River has higher hydropower potential than Bhagirathi River $(1765 \mathrm{~m} / \mathrm{s}$ on average compared to $271 \mathrm{~m} / \mathrm{s}$ in Table 1). However, $1 \mathrm{GW}_{\text {peak }}$ demand in Punjab corresponds to $4584 \mathrm{GWh}$ annual demand which is less than the annual demand in Delhi when the total demand is scaled to $1 \mathrm{GW}_{\text {peak. In }}$ our analysis, although Chenab has much more hydropower potential it is observed that in the integrated system the hydropower generated in Bhagirathi is also being sent to Punjab which can be explained by the intermittency of the streamflows. In addition, when we performed the same analysis by switching the demand point and basin pairs, we observed that the overall cost is reduced by $38 \%$ by using $63 \%$ less diesel in the integrated system, compared to Bhagirathi-Punjab and Chenab-Delhi isolated cases.

\subsection{Effect of water amount in resource sharing}

In the special case above where we set the solar capacity to $1 \mathrm{GW}_{\text {peak }}$ at both states, the system tends to use hydropower as much as possible by using the water in the reservoirs as the diesel is an expensive alternative. Therefore, the benefit that we gain from the integrated system is highly dependent on the available streamflow in the system. To show the effect of available water amount on the benefit of integrated systems over the isolated systems, we performed an analysis by scaling the streamflow data for all scenarios and time periods from $20 \%$ to $200 \%$ compared to the original case and in Fig. 8 we show how the results change based on this scaling. It is expected that when hydropower potential increases the benefit of resource sharing increases both in terms of the penalty due to diesel contribution to meet the demand and the total cost (Fig. 8a-b). However, the change in the total reservoir size is not obvious. In Fig. $8 c$, it is interesting to see that when the hydropower potential is low, the integrated system requires more investment on storage (total reservoir is larger) compared to the isolated cases and it requires less (total reservoir is smaller) in case of high hydropower potential. Therefore, reduction in total cost does not always mean smaller reservoir and its size is related to streamflow available that can be used immediately without being stored.

\subsection{Optimal solar power}

In Section 5.1, we analyzed the hydropower generation and storage capacity needed to support $1 \mathrm{GW}_{\text {peak }}$ solar capacity by fixing the solar panel area. Here, we relax this constraint to find the optimal value of the solar capacity based on the cost parameters given in Table 7 .

When solar capacity is not fixed to $1 \mathrm{GW}_{\text {peak, }}$ we obtain results with smaller solar panel areas $\left(7.98 \mathrm{~km}^{2}\right.$ in Delhi and $5.54 \mathrm{~km}^{2}$ in Punjab) and end up with smaller peak solar capacity (0.90 GW $\mathrm{Geak}_{\text {pea }}$ in Delhi and $0.61 \mathrm{GW}_{\text {peak }}$ in Punjab) with almost the same size reservoirs and transmission lines compared to the case presented in Fig. 7. Expected contributions of hydro, solar and diesel to meet the demand are observed as 61\%, 30\% and 9\% for Delhi and 68\%, 23\% and 9\% for Punjab, respectively. The expected unit cost of the system is further reduced to $₫ 4.9 \mathrm{kWh}^{-1}$ from $₫ 5.1 \mathrm{kWh}^{-1}$ as we relax two constraints in the model. As the systems generates less solar energy, contribution of hydro and even diesel increases. The distribution of supply alternatives to meet the demand for all 53 scenarios is given in Fig. 9 sorted in the increasing hydro contribution. It can be seen that solar contribution is quite constant for different scenarios and hydropower availability determines the diesel contribution which varies between $0 \%$ and $20 \%$. The distribution of hydro, solar and diesel contribution throughout the year can also be seen in Fig. 10. We see that solar energy contribution is quite constant throughout the year with some fluctuations in the Monsoon. Hydro and diesel work as complementary to each other.

Here, it is interesting to see that although solar power are much cheaper than diesel on a levelized basis, significant diesel contribution is needed due to intermittency of both solar radiation and streamflows.

In our formulation, we allow excessive solar energy to be spilled. This means that some of the solar energy generated may not be used to fulfill the demand. In order to see if allowing spill is
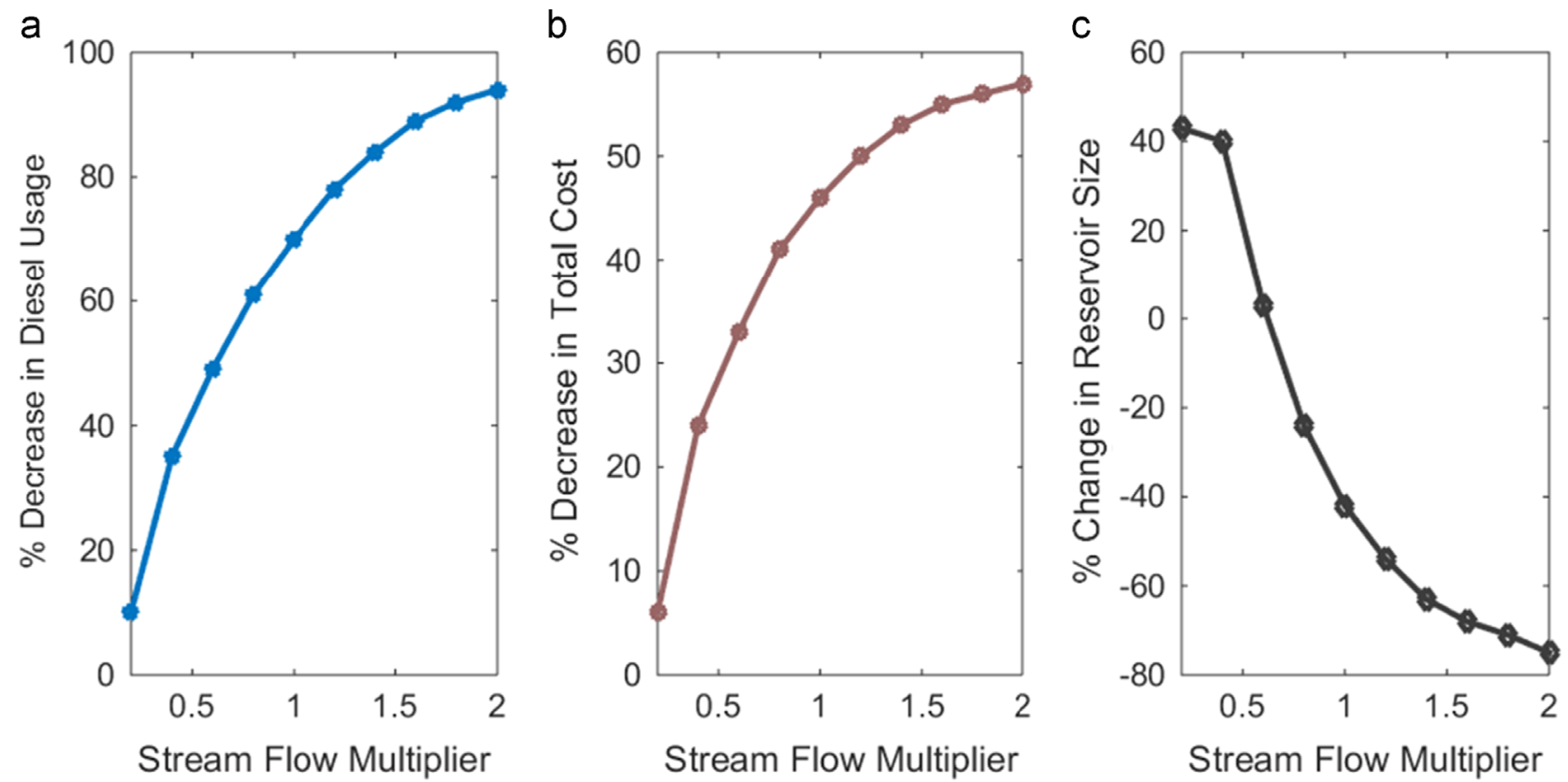

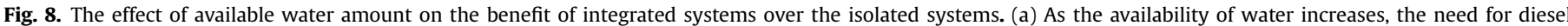

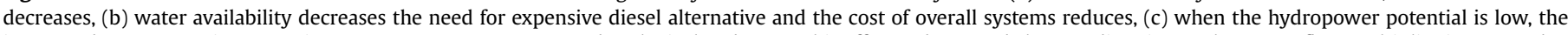

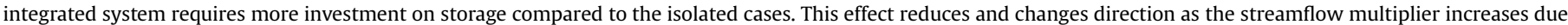
to more availability of streamflow that can be used immediately without being stored. 
a

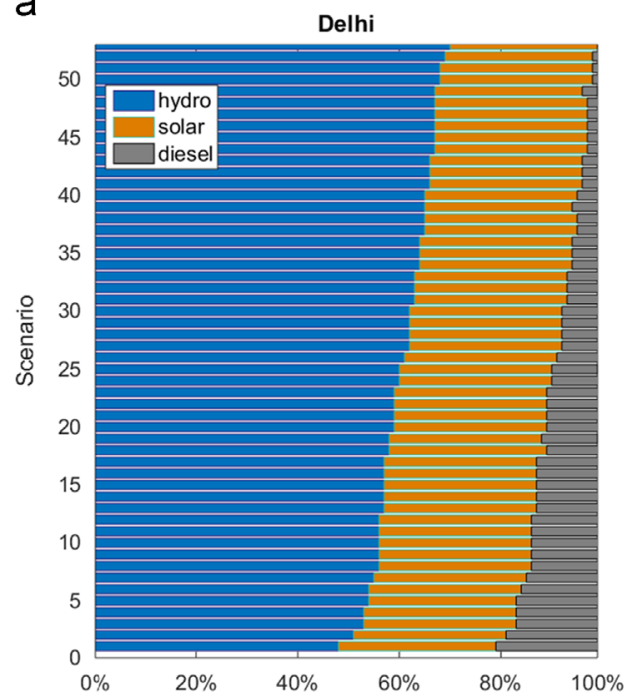

b

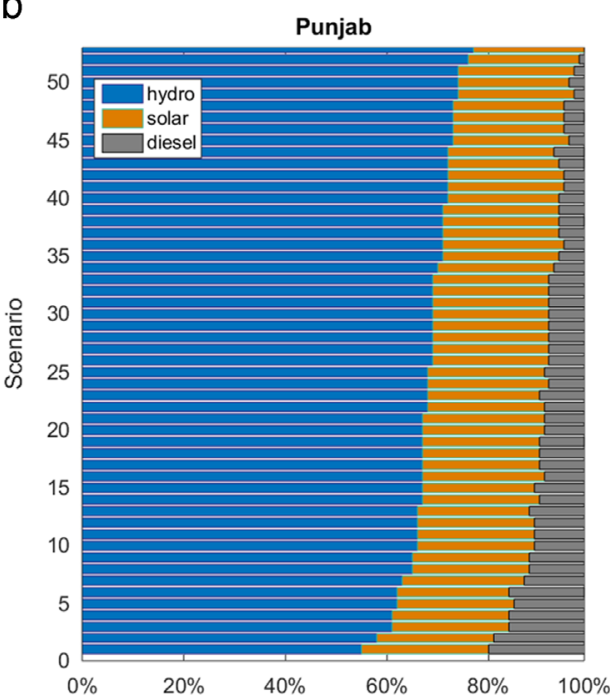

Fig. 9. The distribution of sources to meet the $100 \%$ demand for 53 scenarios (a) in Delhi, (b) in Punjab.

a

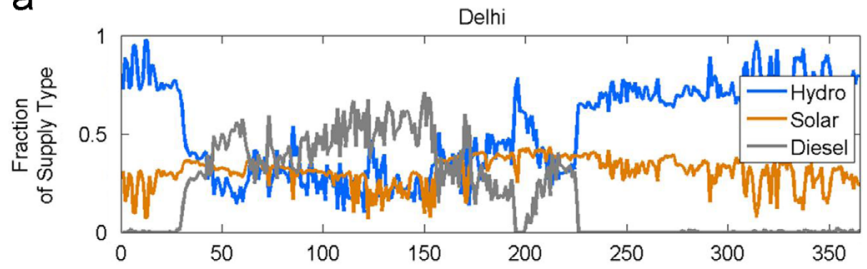

b

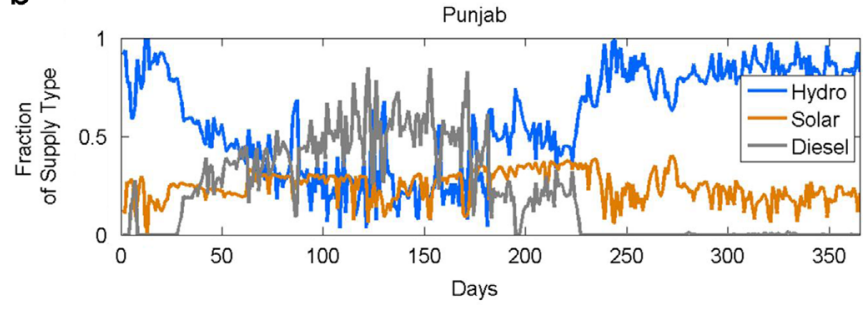

Fig. 10. Contribution of each "fuel" (supply) type that has been used to meet the demand through the year for each day starting from September. (a) in Delhi, (b) in Punjab. Solar energy contribution is quite constant throughout the year with some fluctuations in the Monsoon. Hydro and diesel work as complementary to each other.

a profitable decision, we replaced the inequality in constraint (8) of the formulation with equality to force the system to use all the renewable energy. It is interesting to see that when we do not allow solar energy to be spilled, the unit cost of the system increased to $₫ 5.2 \mathrm{kWh}^{-1}$ (from $₫ 4.9 \mathrm{kWh}^{-1}$ ). Fig. 11 shows the solar energy production and demand for the systems when some renewable energy is spilled and when it is not spilled. In Fig. 11 the orange area (solar) above the gray area (demand) represents electricity being spilled.

Results here show that if the output of the solar power stations can be controlled (i.e. spill is allowed), operating them below their maximum energy generation levels may reduce the unit cost of the system. However, one should note that this amount is subject to change depending on the time scale considered for dispatch of solar power and the ancillary services that might be considered to provide. An interesting study which shows the effects of wind control methods on the power systems economics can be found in [57]. a

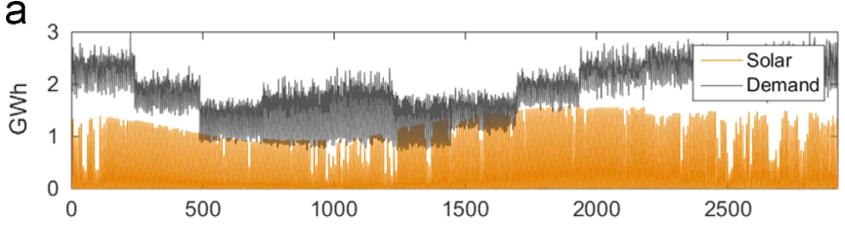

b

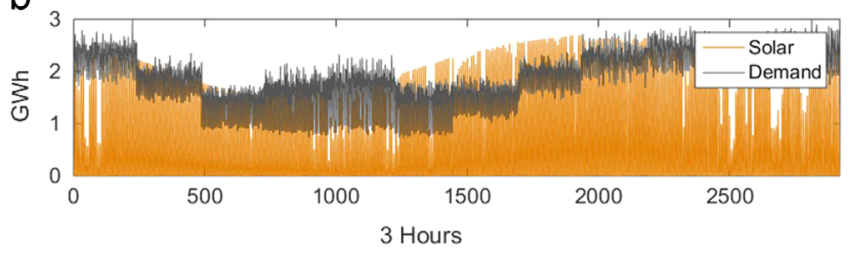

Fig. 11. (a) Solar production and demand throughout the year (starting from September) when solar spill is not allowed. At none of the 3 hourly time intervals, solar generation can exceed the demand, (b) Solar production and demand when solar spill is allowed. Orange area (solar) above the gray area (demand) represents electricity being spilled. It can be seen that solar energy is mostly spilled between February and April.

\subsection{Fixed diesel contribution}

In previous sections, we quantify the effect of intermittency of solar radiation and streamflow focusing on the diesel contribution to meet the demand. We show that even with the advantage of resource sharing, for some scenarios diesel contribution may go up to $20 \%$. However, one may want to design a system that is truly renewable or with limited fossil fuels. Here, we put a constraint on the diesel usage for all scenarios in the model and we develop the sizing relationship between solar and hydro in a minimal fossil fuel generation setting.

When we set an equation which mandates the diesel contribution to be equal to zero for all scenarios, we obtain an infeasible solution. Therefore, we can say that given these resources, it is not possible to design a zero carbon system and intermittent sources should be supported to have a reliable system even though their install capacity exceed the demand. We set a constraint which mandates the diesel contribution to meet the demand to be less than or equal to the values between $1 \%$ and $20 \%$ (which is the highest value in Fig. 9). In Fig. 12 we show how the infrastructure sizes change as we relax diesel contribution in the model. As expected, the system tends to increase the solar panel area and the reservoir size to store more energy as we restrict the 
a

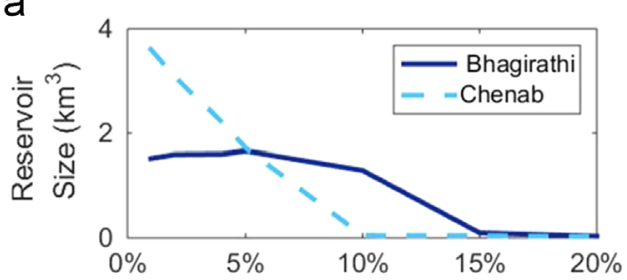

C

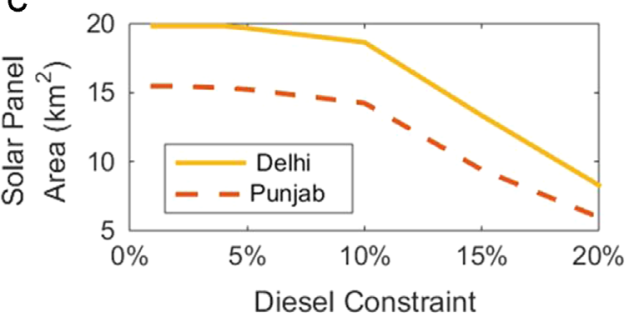

b

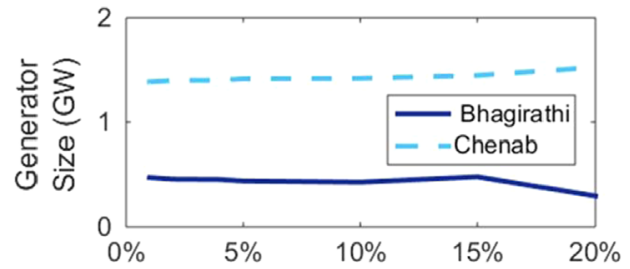

d

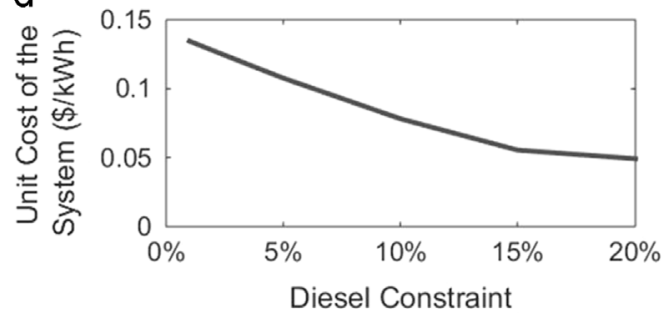

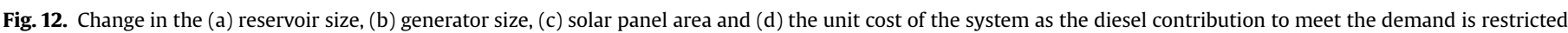
with some percentage for all scenarios.

diesel usage. Here, what may be surprising is the curve shapes that we observe when we restrict diesel usage in steps of $5 \%$. The quite different response for the two different rivers can be explained by their streamflow potentials. The average streamflow potential is approximately eight times more in Chenab than Bhagirathi and without increasing the size of the reservoir significantly, it is possible to increase the hydropower output. However, in Bhagirathi River the increased hydropower generation can only be achieved by storing more water. That's why the reservoir size is much larger in Bhagirathi when the diesel restriction is around $10 \%$ In addition, when there is very little diesel available, the reservoir size in Chenab can still be increased significantly as there is available water to store, however; in Bhagirathi river increasing reservoir size does not help to increase hydropower output as the availability of streamflow restricts the hydropower generation. Increasing solar panel area does not help in the first half of the figure as much as in the second half because when we increase the solar panel area, the amount of spilled solar energy increases and contribution of increasing solar panel area decreases. Here, the fact that $10 \%$ seems like a critical point for the infrastructure sizes can be explain by expected diesel contribution being around $9 \%$ in the optimal scenario where we do not restrict any source type.

\subsection{Multi demand point-multi basin}

In this section, we present a case study which includes all the basins and demand points of India shown in Fig. 3 to show the hydro and solar relationship while supporting $1 \mathrm{GW}_{\text {peak }}$ solar generation to meet $1 \mathrm{GW}_{\text {peak }}$ demand. $7.71 \mathrm{GW}$ hydropower generation capacity (sum of eight basins) should be installed and at each basin (except for Dibang) hydropower generation should be supported by reservoirs in the order of $0.01 \mathrm{~km}^{3}$. Table 8 summarizes the results and shows the proposed sizes for reservoirs and generators for each basin. As the size of the model quickly rises with the number of demand points and basins, we reduced the number scenarios from 53 years to 9 years by choosing the rainiest and the driest years for all the basins.

With a $437 \mathrm{~km}^{3}$ average annual inflow, the Siang River has by far the highest potential and provides electricity to almost all the states in the case study. Due to high hydropower potential in Siang River, the model proposes to build the largest hydropower station on this river and use long distance transmission lines to transmit energy to further demand points. One should keep in mind that in our model we do not include lower/upper bounds for reservoir sizes nor generator capacities. Other environmental and geographic constraints or
Table 8

Size of the Hydropower Stations Proposed for Basins.

\begin{tabular}{lrrrll}
\hline Rivers & \multicolumn{2}{l}{$\begin{array}{l}\text { Annual Inflow } \\
\left(\mathrm{km}^{3}\right)\end{array}$} & \multicolumn{3}{c}{$\begin{array}{l}\text { Reservoir size } \\
\left(\mathrm{km}^{3}\right)\end{array}$} \\
\cline { 2 - 4 } & min & mean & $\begin{array}{l}\text { Generator size } \\
(\mathrm{GW})\end{array}$ \\
\hline Bhagirathi & 3.05 & 6.86 & 13.51 & 0.03 & \\
Pinder & 3.59 & 5.26 & 7.71 & 0.01 & 0.29 \\
Chenab & 21.05 & 56.09 & 87.93 & 0.02 & 0.23 \\
Marusudar & 5.55 & 14.79 & 23.19 & 0.01 & 1.15 \\
Lohit & 12.78 & 18.92 & 24.00 & 0.01 & 0.35 \\
Dibang & 6.26 & 8.95 & 11.71 & 0.00 & 0.29 \\
Barak & 28.13 & 66.06 & 95.72 & 0.01 & 0.19 \\
Siang & 286.54 & 437.56 & 571.32 & 0.06 & 0.93 \\
\hline
\end{tabular}

Table 9

Solar panel areas and energy generation by type.

\begin{tabular}{llllll}
\hline Demand points & $\begin{array}{l}\text { Demand } \\
\text { GWh } \\
\left(1 \mathrm{GW}_{\text {peak }}\right)\end{array}$ & $\begin{array}{l}\text { Solar panel } \\
\text { area km }\end{array}$ & \multicolumn{3}{l}{$\begin{array}{l}\text { Expected energy genera- } \\
\text { tion (\%Demand) }\end{array}$} \\
\cline { 4 - 6 } & & $\left(1 \mathrm{GW}_{\text {peak }}\right)$ & Hydro & Solar & Diesel \\
\hline Delhi & 5525 & 8.87 & 66 & 32 & 2 \\
Punjab & 4585 & 9.15 & 65 & 33 & 2 \\
Uttarankhand & 2019 & 9.05 & 59 & 38 & 3 \\
Himachal Pradesh & 4943 & 8.85 & 66 & 33 & 1 \\
Uttar Pradesh & 6250 & 9.55 & 70 & 29 & 1 \\
Bihar & 5903 & 9.27 & 70 & 29 & 1 \\
West Bengal & 6147 & 9.47 & 70 & 29 & 1 \\
Jharkhand & 4996 & 8.99 & 66 & 33 & 1 \\
Assam & 4425 & 9.05 & 70 & 29 & 1 \\
Chhattisgarh & 6181 & 9.20 & 68 & 31 & 1 \\
\hline
\end{tabular}

water sharing agreements between countries, which are specific to basins, are also out of the scope of this paper.

The expected unit cost of the system is 3.7 cents $/ \mathrm{kWh}$. In Table 9, the solar panel areas that are need to generate $1 \mathrm{GW}_{\text {peak }}$ solar power in each demand point are presented. We also present the expected energy generation by source type. It can be seen that $1 \mathrm{GW}_{\text {peak }}$ solar power generation can contribute to meet only $30 \%$ of the demand. Although annual sum of the hydro and solar energy potential is more than the demand, diesel contribution for the around $1 \%$ of the demand is still more cost efficient due to the seasonality and intermittency of the renewable sources. 
Table 10

Transmission line capacities between basins and demand point.

\begin{tabular}{|c|c|c|c|c|c|c|c|c|c|c|}
\hline Rivers/states (GW) & Delhi & Punjab & Uttarakhand & Himalach Pradesh & Uttar Pradesh & Bihar & West Bengal & Jharkhand & Assam & Chhattisgarh \\
\hline Bhagirathi & 0.07 & 0.21 & 0.29 & 0.08 & 0.00 & 0.00 & 0.00 & 0.00 & 0.00 & 0.09 \\
\hline Pinder & 0.05 & 0.07 & 0.16 & 0.00 & 0.12 & 0.00 & 0.00 & 0.00 & 0.00 & 0.08 \\
\hline Chenab & 0.42 & 0.19 & 0.17 & 0.35 & 0.05 & 0.02 & 0.00 & 0.00 & 0.00 & 0.00 \\
\hline Marusudar & 0.00 & 0.23 & 0.13 & 0.07 & 0.04 & 0.02 & 0.00 & 0.00 & 0.00 & 0.00 \\
\hline Lohit & 0.00 & 0.00 & 0.00 & 0.00 & 0.00 & 0.00 & 0.26 & 0.00 & 0.02 & 0.00 \\
\hline Dibang & 0.01 & 0.00 & 0.00 & 0.06 & 0.07 & 0.04 & 0.00 & 0.01 & 0.00 & 0.01 \\
\hline Barak & 0.01 & 0.00 & 0.09 & 0.00 & 0.07 & 0.00 & 0.32 & 0.03 & 0.36 & 0.21 \\
\hline Siang & 0.39 & 0.27 & 0.07 & 0.29 & 0.59 & 0.84 & 0.36 & 0.64 & 0.55 & 0.54 \\
\hline
\end{tabular}

Table 11

Sensitivity analysis for diesel cost.

\begin{tabular}{|c|c|c|c|c|c|c|c|c|c|c|}
\hline & \multicolumn{2}{|c|}{$\mu_{j}=\$ 0.15 / \mathrm{kWh}$} & \multicolumn{2}{|c|}{$\mu_{j}=\$ 0.2 / \mathrm{kWh}$} & \multicolumn{2}{|c|}{$\mu_{j}=\$ 0.25 / \mathrm{kWh}$} & \multicolumn{2}{|c|}{$\mu_{j}=\$ 0.30 / \mathrm{kWh}$} & \multicolumn{2}{|c|}{$\mu_{j}=\$ 0.35 / \mathrm{kWh}$} \\
\hline & Bhagirathi & Chenab & Bhagirathi & Chenab & Bhagirathi & Chenab & Bhagirathi & Chenab & Bhagirathi & Chenab \\
\hline Reservoir size $\left(\mathrm{km}^{3}\right)$ & 0.020 & 0.020 & 0.025 & 0.022 & 0.031 & 0.024 & 0.037 & 0.025 & 0.042 & 0.027 \\
\hline Generator size (GW) & 0.253 & 1.513 & 0.263 & 1.523 & 0.270 & 1.532 & 0.292 & 1.539 & 0.298 & 1.542 \\
\hline \multicolumn{11}{|l|}{ Transmission line (GW) } \\
\hline Delhi & 0.141 & 0.771 & 0.145 & 0.786 & 0.146 & 0.791 & 0.153 & 0.794 & 0.153 & 0.797 \\
\hline \multirow[t]{2}{*}{ Punjab } & 0.182 & 0.743 & 0.208 & 0.737 & 0.217 & 0.741 & 0.227 & 0.745 & 0.230 & 0.745 \\
\hline & Delhi & Punjab & Delhi & Punjab & Delhi & Punjab & Delhi & Punjab & Delhi & Punjab \\
\hline Solar panel size $\left(\mathrm{km}^{2}\right)$ & 5.461 & 2.968 & 7.087 & 5.073 & 7.988 & 5.542 & 8.373 & 6.015 & 8.671 & 6.419 \\
\hline Expected & & & & & & & & & & \\
\hline Hydro (\%) & $66 \%$ & $74 \%$ & $63 \%$ & $69 \%$ & $61 \%$ & $68 \%$ & $61 \%$ & $68 \%$ & $60 \%$ & $67 \%$ \\
\hline Solar (\%) & $22 \%$ & $13 \%$ & $27 \%$ & $21 \%$ & $30 \%$ & $23 \%$ & $30 \%$ & $24 \%$ & $32 \%$ & $25 \%$ \\
\hline Diesel (\%) & $12 \%$ & $13 \%$ & $10 \%$ & $10 \%$ & $9 \%$ & $9 \%$ & $9 \%$ & $8 \%$ & $8 \%$ & $8 \%$ \\
\hline Cost (Cents/kWh) & 0.039 & & 0.044 & & 0.049 & & 0.053 & & 0.058 & \\
\hline
\end{tabular}

Table 12

Sensitivity analysis with the unit cost of reservoirs.

\begin{tabular}{|c|c|c|c|c|c|c|c|c|c|c|}
\hline & \multicolumn{2}{|l|}{$C_{s}=\$ 1 / \mathrm{m}^{3}$} & \multicolumn{2}{|l|}{$C_{s}=\$ 2 / \mathrm{m}^{3}$} & \multicolumn{2}{|l|}{$C_{s}=\$ 3 / \mathrm{m}^{3}$} & \multicolumn{2}{|l|}{$C_{s}=\$ 4 / \mathrm{m}^{3}$} & \multicolumn{2}{|l|}{$C_{s}=\$ 5 / \mathrm{m}^{3}$} \\
\hline & Bhagirathi & Chenab & Bhagirathi & Chenab & Bhagirathi & Chenab & Bhagirathi & Chenab & Bhagirathi & Chenab \\
\hline Reservoir size $\left(\mathrm{km}^{3}\right)$ & 0.713 & 0.511 & 0.053 & 0.027 & 0.031 & 0.024 & 0.021 & 0.023 & 0.016 & 0.022 \\
\hline Generator size (GW) & 0.336 & 0.145 & 0.275 & 0.152 & 0.270 & 1.533 & 0.268 & 1.542 & 0.273 & 1.549 \\
\hline \multicolumn{11}{|l|}{ Transmission line (GW) } \\
\hline Delhi & 0.165 & 0.772 & 0.152 & 0.785 & 0.146 & 0.791 & 0.143 & 0.795 & 0.141 & 0.798 \\
\hline \multirow[t]{2}{*}{ Punjab } & 0.280 & 0.674 & 0.222 & 0.733 & 0.217 & 0.741 & 0.211 & 0.747 & 0.207 & 0.751 \\
\hline & Delhi & Punjab & Delhi & Punjab & Delhi & Punjab & Delhi & Punjab & Delhi & Punjab \\
\hline Solarpanelsize $\left(\mathrm{km}^{2}\right)$ & 7.8586 & 5.465 & 7.987 & 5.554 & 7.987 & 5.542 & 7.987 & 5.529 & 7.987 & 5.530 \\
\hline \multicolumn{11}{|l|}{ Expected } \\
\hline Hydro (\%) & $66 \%$ & $73 \%$ & $61 \%$ & $68 \%$ & $61 \%$ & $68 \%$ & $61 \%$ & $68 \%$ & $61 \%$ & $68 \%$ \\
\hline Solar (\%) & $28 \%$ & $21 \%$ & $30 \%$ & $23 \%$ & $30 \%$ & $23 \%$ & $30 \%$ & $23 \%$ & $30 \%$ & $23 \%$ \\
\hline Diesel (\%) & $6 \%$ & $6 \%$ & $9 \%$ & $9 \%$ & $9 \%$ & $9 \%$ & $9 \%$ & $9 \%$ & $9 \%$ & $9 \%$ \\
\hline Cost (Cents/kWh) & 0.0476 & & 0.0487 & & 0.0491 & & 0.0493 & & 0.0496 & \\
\hline
\end{tabular}

Table 13

Sensitivity analysis for unit cost of solar panel.

\begin{tabular}{|c|c|c|c|c|c|c|c|c|c|c|}
\hline & \multicolumn{2}{|c|}{$C_{M}=\$ 100 / \mathrm{m}^{2}$} & \multicolumn{2}{|c|}{$C_{M}=\$ 150 / \mathrm{m}^{2}$} & \multicolumn{2}{|c|}{$C_{M}=\$ 200 / \mathrm{m}^{2}$} & \multicolumn{2}{|c|}{$C_{M}=\$ 250 / \mathrm{m}^{2}$} & \multicolumn{2}{|c|}{$C_{M}=\$ 300 / \mathrm{m}^{2}$} \\
\hline & Bhagirathi & Chenab & Bhagirathi & Chenab & Bhagirathi & Chenab & Bhagirathi & Chenab & Bhagirathi & Chenab \\
\hline ReservoirSize $\left(\mathrm{km}^{3}\right)$ & 0.030 & 0.025 & 0.032 & 0.025 & 0.031 & 0.024 & 0.031 & 0.024 & 0.032 & 0.023 \\
\hline GeneratorSize (GW) & 0.264 & 1.534 & 0.268 & 0.153 & 0.270 & 1.533 & 0.273 & 1.534 & 0.288 & 1.534 \\
\hline \multicolumn{11}{|l|}{ Transmission Line (GW) } \\
\hline Delhi & 0.148 & 0.789 & 0.147 & 0.791 & 0.146 & 0.791 & 0.145 & 0.793 & 0.147 & 0.791 \\
\hline \multirow[t]{2}{*}{ Punjab } & 0.213 & 0.745 & 0.216 & 0.742 & 0.217 & 0.741 & 0.217 & 0.741 & 0.214 & 0.744 \\
\hline & Delhi & Punjab & Delhi & Punjab & Delhi & Punjab & Delhi & Punjab & Delhi & Punjab \\
\hline SolarPanelSize $\left(\mathrm{km}^{2}\right)$ & 10.200 & 7.695 & 8.591 & 6.264 & 7.987 & 5.542 & 7.086 & 5.078 & 5.893 & 3.993 \\
\hline \multicolumn{11}{|l|}{ Expected } \\
\hline Hydro (\%) & $58 \%$ & $64 \%$ & $60 \%$ & $67 \%$ & $61 \%$ & $68 \%$ & $63 \%$ & $69 \%$ & $65 \%$ & $72 \%$ \\
\hline Solar (\%) & $34 \%$ & $29 \%$ & $31 \%$ & $25 \%$ & $30 \%$ & $23 \%$ & $27 \%$ & $21 \%$ & $23 \%$ & $17 \%$ \\
\hline Diesel (\%) & $8 \%$ & $7 \%$ & $8 \%$ & $8 \%$ & $9 \%$ & $9 \%$ & $10 \%$ & $9 \%$ & $12 \%$ & $11 \%$ \\
\hline Cost (Cents/kWh) & 0.0394 & & 0.0445 & & 0.0491 & & 0.0532 & & 0.0568 & \\
\hline
\end{tabular}


The major transmission lines ( $\geq 0.2 \mathrm{GW}$ ) between hydropower stations and demand points can be seen in Table 10. The first four basins listed in the tables are located in the northern part of India and the others are located in the north-east region. An important result confirming the findings above is that high streamflow potential of the basins in the north-east region are useful in fulfilling the demand of northern states and high capacity long transmission lines are preferred instead of local diesel generators within demand points.

\section{Sensitivity analysis}

In this section, we present a sensitivity analysis to inspect how sensitive our model is to the cost parameters. This type of analysis can provide meaningful insight about differences in the optimal solution of the problem in response to small changes in the cost parameters.

We used $\$ 0.25 \mathrm{kWh}^{-1}, \$ 3 / \mathrm{m}^{3}$, and $\$ 250 / \mathrm{m}^{2}$ as the unit cost of diesel generation, reservoir size and solar panel area respectively. The diesel component of the network is the expensive alternative as we assumed that there is a penalty fee for each unit of electricity that could not be generated using renewable sources. Therefore, our model compares that marginal cost of unit diesel cost with the marginal cost of renewable sources. For example, if increasing the size of the reservoir to generate an additional $\mathrm{kWh}$ of hydro energy (without causing any size increase in generator or transmission lines) is cheaper than the unit cost of diesel, the model increases the size of the reservoir. Tables 11-13 summarize the sensitivity analysis performed for the unit costs.

\section{Conclusion}

We presented a two-stage stochastic program to help infrastructure planners determine the optimal capacities of hydropower and solar power infrastructure needed to match projected demand and supply in the most cost effective way. We considered fine-grained sources of variability such as streamflow, solar radiation at the hourly level as well as the spatial location of supply and demand at the national/regional level. It is expected that with the help of continuously improved technologies, solar power will be highly utilized at utility scale and it will become more attractive to consumers over the next two decades as prices decline. Due to intermittency of the solar power, it must be supported by storage systems or should be designed together with a kind of controllable source.

In this paper, we asked whether the solar power potential in India can be supported by the high hydropower potential in Himalaya Mountains and how we should size the hydropower generation capacity and reservoirs to support fixed amount of peak solar capacity. The Himalayas are interesting because it tends to have very steep basins with significant effects from the seasonal snowpack, the monsoon, and glacial melt. The streamflow data has significant seasonal and inter-annual variability and diesel generators (as a proxy for expensive fossil resources) are used as a backup source to increase the reliability of the system. With our analysis using real and modeled data, we show that hydropower capacity needed to support solar power is heavily site-dependent and reservoir capacity changes significantly with the amount of streamflow available through the year.

Moreover, with today's technology and cost structure, it is possible to significantly reduce fossil fuel's role in electricity generation using solar and hydropower in India. The design of connected systems through inter-regional transmission introduces the benefits of geographic diversification and resource sharing and help reduce the need for back up fossil fuels further. We finally showed that if the output of the solar power stations can be controlled (i.e. spill is allowed or solar power is curtailed), operating them below their maximum energy generation levels may reduce the unit cost of the system.

\section{References}

[1] Key World Energy Statistics. International Energy Agency; 2014.

[2] Ashok S. Optimised model for community-based hybrid energy system. Renew Energy 2007;32(7):1155-64.

[3] Ekren O, Ekren BY. Size optimization of a PV/wind hybrid energy conversion system with battery storage using simulated annealing. Appl Energy 2010; 87(2):592-8.

[4] Ekren O, Ekren BY, Ozerdem B. Break-even analysis and size optimization of a PV/wind hybrid energy conversion system with battery storage-a case study. Appl Energy 2009;86(7):1043-54.

[5] Mallah S, Bansal NK. Allocation of energy resources for power generation in India: business as usual and energy efficiency. Energy Policy 2010;38(2):1059-66.

[6] Cormio C, Dicorato M, Minoia A, Trovato M. A regional energy planning methodology including renewable energy sources and environmental constraints. Renew Sustain Energy Rev 2003:7(2):99-130.

[7] NEMS. The National Energy Modeling System: An Overview, Technical Report Energy information administration, Office of Integrated Analysis and Forecasting, U.S. Department of Energy, Washington, DC 20585; 2003.

[8] Loulou R, Goldstein G, Noble K. Documentation for the MARKAL family of models Technical report, Energy Technology Systems Analysis Programme; 2004.

[9] Fishbone LG, Abilock H. Markal, a linear-programming model for energy systems analysis: Technical description of the bnl version. Int J Energy Res 1981;5(4):353-75.

[10] Lamont AD. Assessing the long-term system value of intermittent electric generation technologies. Energy Econ 2008;30(3):1208-31.

[11] Kuznia L, Zeng B, Centeno G, Miao Z. Stochastic optimization for power system configuration with renewable energy in remote areas. Ann Op Res 2013; 210(1):411-32.

[12] Krishnan V, Das T, Ibanez E, Lopez CA, McCalley JD. Modeling operational effects of wind generation within national long-term infrastructure planning software. Palmintier B, Webster M. IEEE Transactions on Power Systems (2011, July). 28 2; 2013. p. 1308-1317.

[13] Impact of unit commitment constraints on generation expansion planning with renewables. In: Power and Energy Society General Meeting, IEEE; 2011. (pp. 1-7).

[14] Short W, Sullivan P, Mai T, Mowers M, Uriarte C, Blair N, et al. Regional energy deployment system (ReEDS). Contract 2011;303:275-3000.

[15] Das T, Krishnan V, McCalley JD. High-fidelity dispatch model of storage technologies for production costing studies. IEEE Trans Sustain Energy 2014; 5(4):1242-52.

[16] Ahn SJ, Graczyk D. Understanding energy challenges in India: policies, players, and issues. Paris: IEA; 2012.

[17] Suganthi L, Williams A. Renewable energy in India-a modelling study for 2020-2021. Energy Policy 2000;28(15):1095-109.

[18] Singh P, Jain SK. Snow and glacier melt in the Satluj River at Bhakra Dam in the western Himalayan region. Hydrol Sci J 2002;47(1):93-106.

[19] Sharma NK, Tiwari PK, Sood YR. Solar energy in India: strategies, policies, perspectives and future potential. Renew Sustain Energy Rev 2012;16(1):933-41.

[20] Kocaman AS. Essays on infrastructure design and planning for clean energy systems. Doctoral dissertation. Columbia University; 2014.

[21] Førsund F. Hydro Power Economics. International Series in Operations Research and Management Science 2007.

[22] Ruiz-Mier F, Ginneken MV. India's Water Economy: Bracing for a Turbulent Future; 2008

[23] S. Dharmadhikary. Mountains of concrete: Dam building in the Himalayas; 2008. (No. id: 1815).

[24] Barlev D, Vidu R, Stroeve P. Innovation in concentrated solar power. Sol Energy Mater Sol Cells 2011:95(10):2703-25.

[25] Mousazadeh H, Keyhani A, Javadi A, Mobli H, Abrinia K, Sharifi A. A review of principle and sun-tracking methods for maximizing solar systems output. Renew Sustain Energy Rev 2009;13(8):1800-18.

[26] Parida B, Iniyan S, Goic R. A review of solar photovoltaic technologies. Renew Sustain Energy Rev 2011;15(3):1625-36.

[27] Sanoh A, Kocaman AS, Kocal S, Sherpa S, Modi V. The economics of clean energy resource development and grid interconnection in Africa. Renew Energy 2014;62:598-609.

[28] Zvoleff A, Kocaman AS, Huh WT, Modi V. The impact of geography on energy infrastructure costs. Energy Policy 2009:37(10):4066-78.

[29] Kocaman AS, Huh WT, Modi V. Initial layout of power distribution systems for rural electrification: a heuristic algorithm for multilevel network design. Appl Energy 2012;96:302-15.

[30] Wu F, Varaiya P, Spiller P, Oren S. Folk theorems on transmission access: Proofs and counterexamples. J Regul Econ 1996;10(1):5-23.

[31] Liu A, Hobbs BF, Ho J, McCalley J, Krishnan V, Shahidehpour M, et al. Cooptimization of transmission and other supply resources. Prepared for the Eastern Interconnection States' Planning Council. NARUC; 2013. 
[32] Krishnan V, McCalley JD, Lemos S, Bushnell J. Nation-wide transmission overlay design and benefits assessment for the US. Energy Policy 2013;56:221-32.

[33] National Renewable Energy Laboratory. In: Hand MM, Baldwin S, DeMeo E, Reilly JM, Mai T, Arent D, Porro G, Meshek M, Sandor D, editors. Renewable Electricity Futures Study, 4 vol.. Golden, CO: National Renewable Energy Laboratory; 2012 NREL/TP-6A20-52409.

[34] Li Y, McCalley JD. Design of a high capacity inter-regional transmission overlay for the US. IEEE Trans Power Syst 2015;30(1):513-21.

[35] Bent R, Berscheid A, Toole GL. Generation and transmission expansion planning for renewable energy integration. In: Power Systems Computation Conference (PSCC); 2011.

[36] Tejada-Guibert JA, Johnson SA, Stedinger JR. The value of hydrologic information in stochastic dynamic programming models of a multireservoir system. Water Resourc Res 1995;31(10):2571-9.

[37] Liang X, Lettenmaier D, Wood E, Burges S. A simple hydrologically based model of land surface water and energy fluxes for general circulation models. J Geophys Res 1994;99(14):414-5.

[38] Liang X, Wood EF, Lettenmaier DP. Surface soil moisture parameterization of the VIC-2L model: evaluation and modification. Glob Planet Change 1996;13(1): 195-206.

[39] Sheffield J, Wood EF. Characteristics of global and regional drought, 1950-2000: analysis of soil moisture data from off-line simulation of the terrestrial hydrologic cycle. J Geophys Res: Atmos 2007;112(D17):1984-2012.

[40] Sheffield J, Goteti G, Wood EF. Development of a 50-year high-resolution global dataset of meteorological forcings for land surface modeling. J Clim 2006;19(13):3088-111.

[41] 〈http://www.cea.nic.in/executive_summary.html〉. [accessed 18.10.13].

[42] Statistical Abstract of Delhi. Directorate of Economics and Statistics; 2012.

[43] 〈http://rredc.nrel.gov/solar/new_data/India/about.html〉 [accessed 18.10.13].

[44] 〈http://www-01.ibm.com/software/info/ilog/〉 [accessed 20.11.13].

[45] Krishnan V., McCalley JD. Building Foresight in Long-Term Infrastructure Planning Using End-Effect Mitigation Models; 2015.
[46] Lempérière F. Dam design and construction, reservoirs and balancing lakes; 2013. Retrieved from: 〈http://www.hydrocoop.org $\rangle$.

[47] Keller AA, Sakthivadivel R, Seckler DW. Water scarcity and the role of storage in development 2000; vol. 39.

[48] OpenEI Transparent Cost Database [accessed 12.10.13].

[49] World Energy Perspective, Cost of Energy Technologies. World Energy Council; 2013.

[50] 〈http://www.renewableenergyworld.com/articles/2011/12/solar-powerbecomes-cheaper-than-diesel-in-india.html [accessed 04.30.15].

[51] Khan MJ, Iqbal MT. Pre-feasibility study of stand-alone hybrid energy systems for applications in Newfoundland. Renew Energy 2005;30(6):835-54.

[52] Ekholm T, Krey V, Pachauri S, Riahi K. Determinants of household energy consumption in India. Energy Policy 2010;38(10):5696-707.

[53] Kumar A, Schei T, Ahenkorah A, Caceres Rodriguez R, Devernay J-M, Freitas M, et al. Hydropower. In: Edenhofer O, Pichs-Madruga R, Sokona Y, Seyboth K, Matschoss P, Kadner S, et al., editors. IPCC Special Report on Renewable Energy Sources and Climate Change Mitigation. Cambridge, United Kingdom and New York, NY, USA: Cambridge University Press; 2011.

[54] Fthenakis V, Kim HC, Frischknecht R, Raugei M, Sinha P, Stucki M. Life cycle inventories and life cycle assessment of photovoltaic systems. PVPS Task 2011:12.

[55] Czanderna AW, Jorgensen GJ. Service lifetime prediction for encapsulated photovoltaic cells/minimodules. In: AIP Conference Proceedings . IOP Institute of Physics Publishing Ltd.; 1997. p. 295-312.

[56] 〈http://www.eei.org/ourissues/ElectricityTransmission/Documents/Trans_Pro ject_lowres.pdf $\rangle$ [accessed 05.10.15].

[57] Nock D, Krishnan V, McCalley JD. Dispatching intermittent wind resources for ancillary services via wind control and its impact on power system economics. Renew Energy 2014;71:396-400. 